\title{
Luminescent Rhenium(I)tricarbonyl Complexes Containing Different Pyrazoles and Their Successive Deprotonation Products: $\mathrm{CO}_{2}$ Reduction Electrocatalysts
}

\author{
Beatriz Merillas, Elena Cuéllar, Alberto Diez-Varga, Tomás Torroba, Gabriel García-Herbosa, \\ Sergio Fernández, Julio Lloret-Fillol, Jose M. Martín-Alvarez, Daniel Miguel, and Fernando Villafañe*
}

Cite This: https://dx.doi.org/10.1021/acs.inorgchem.0c01654

Read Online

ACCESS | Lلll Metrics \& More | 国 Article Recommendations | (1) Supporting Information

ABSTRACT: Cationic fac-[Re(CO) $\left.{ }_{3}\left(\mathrm{pz}^{*} \mathrm{H}\right)(\mathrm{pypzH})\right] \mathrm{OTf}$ $(\mathrm{pz} * \mathrm{H}=$ pyrazole, $\mathrm{pzH} ; 3,5$-dimethylpyrazole, dmpzH; indazole, indzH; 3-(2-pyridyl)pyrazole, pypzH) were obtained from fac$\left[\operatorname{ReBr}(\mathrm{CO})_{3}(\mathrm{pypzH})\right]$ by halide abstraction with AgOTf and subsequent addition of the corresponding pyrazole. Successive deprotonation with $\mathrm{Na}_{2} \mathrm{CO}_{3}$ and $\mathrm{NaOH}$ gave neutral fac$\left[\operatorname{Re}(\mathrm{CO})_{3}\left(\mathrm{pz}^{*} \mathrm{H}\right)(\mathrm{pypz})\right]$ and anionic $\mathrm{Na}\left\{\mathrm{fac}-\left[\operatorname{Re}(\mathrm{CO})_{3}\left(\mathrm{pz}^{*}\right)-\right.\right.$ $(\mathrm{pypz})]\}$ complexes, respectively. Cationic $f a c-\left[\operatorname{Re}(\mathrm{CO})_{3}\left(\mathrm{pz}^{*} \mathrm{H}\right)\right.$ (pypzH)]OTf, neutral complexes $f a c-\left[\operatorname{Re}(\mathrm{CO})_{3}\left(\mathrm{pz}^{*} \mathrm{H}\right)(\mathrm{pypz})\right]$, and $f a c-\left[\operatorname{Re}(\mathrm{CO})_{3}(\mathrm{pypz})_{2} \mathrm{Na}\right]$ were subjected to photophysical and electrochemical studies. They exhibit phosphorescent decays from

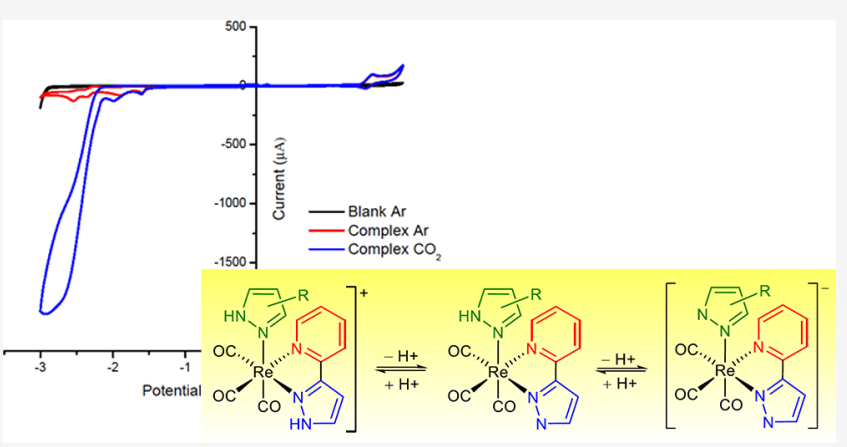
a prevalently ${ }^{3} \mathrm{MLCT}$ excited state with quantum yields $(\Phi)$ in the range between 0.03 and 0.58 and long lifetimes ( $\tau$ from 220 to $869 \mathrm{~ns}$ ). The electrochemical behavior in Ar atmosphere of cationic and neutral complexes indicates that the oxidation processes assigned to $\operatorname{Re}^{\mathrm{I}} \rightarrow \operatorname{Re}^{\mathrm{II}}$ occurs at lower potentials for the neutral complex compared to cationic complex. The reduction processes occur at the ligands and do not depend on the charge of the complexes. The electrochemical behavior in $\mathrm{CO}_{2}$ saturated media is consistent with $\mathrm{CO}_{2}$ electrocatalyzed reduction, where the values of the catalytic activity $\left[i_{\text {cat }}\left(\mathrm{CO}_{2}\right) / i_{\text {cat }}(\mathrm{Ar})\right]$ ranged from 2.7 to 11.5 (compared to 8.1 for $f a c$ - $\left[\operatorname{Re}(\mathrm{CO})_{3} \mathrm{Cl}(\right.$ bipy $\left.)\right]$ studied as a reference). Controlled potential electrolysis for the pyrazole cationic (3a) and neutral (4a) complexes after $1 \mathrm{~h}$ affords CO in faraday yields of 61 and $89 \%$, respectively. These values are higher for indazole complexes and may be related to the acidity of the coordinated pyrazole.

\section{INTRODUCTION}

The first report on the photophysical properties of rhenium(I) tricarbonyl diimine complexes was described 45 years ago. ${ }^{1}$ Since then, this class of compounds has been very intensively studied, and many luminescent $f a c-\left[\operatorname{ReX}(\mathrm{CO})_{3}(\mathrm{~N}-\mathrm{N})\right]$ complexes have been reported, showing rich excited-state properties associated with their long-lived triplet metal-toligand charge transfer $\left({ }^{3} \mathrm{MLCT}\right)$ excited state. ${ }^{2}$ The study of these photophysical properties has led to the development of diverse applications for this type of compounds, such as biomolecular agents, ${ }^{3}$ molecular sensors or photoswitches, ${ }^{4}$ light-emitting devices, ${ }^{5}$ photocatalysts for the reduction of $\mathrm{CO}_{2}{ }^{6}$ or for the production of $\mathrm{H}_{2}$.

These applications are usually the result of an adequate tuning by varying the diimine ligand, the "sixth" ligand " $\mathrm{X}$ " (a halide or pseudohalide for neutral complexes, a neutral ligand for cationic complexes), or the solvent. ${ }^{2}$ An alternative and efficient strategy in order to induce systematic and tunable modifications in the donor/aceptor properties of the ligands emerges from the presence of either acidic hydrogens or protonatable sites. They allow reversible protonation/depro- tonation processes in mild conditions, thus favoring smooth differences in the electron distributions of the ground and the excited states and therefore helping to adjust their photophysical properties. ${ }^{6 c, 8}$ However, there are few reports on the role of ligands able to undergo protonation/deprotonation processes on the chemical and physical properties of rhenium(I) tricarbonyl diimine complexes. The first report described the absorption and luminescent properties of several complexes containing carboxylic acid-functionalized ligands. ${ }^{9}$ The use of diimine ligands bearing acidic phenol substituents ${ }^{10}$ or imidazole groups ${ }^{11}$ and reports on oxazolylidene or tetrazolate moieties as "sixth" ligand ${ }^{12}$ have been described. There are also reports on the involvement of ligands with

Received: June 5, 2020 
acidic hydrogens or protonatable sites in proton-coupled electron transfer (PCET) processes on photoexcited rhenium(I) tricarbonyl diimine complexes. ${ }^{13}$

Following our aim to design systems which allow a systematic control of both the electronic and steric properties of the ligands coordinated to the $\left.f a c-\left[\operatorname{Re}^{\mathrm{I}}(\mathrm{CO})_{3}\right)\right]$ fragment, ${ }^{14}$ we devised a family of complexes designated to allow successive deprotonations in order to obtain cationic, neutral, and anionic compounds with similar ligands but different electronic and steric properties. Herein we report the syntheses and photophysical and electrochemical properties of cationic fac- $\left[\operatorname{Re}(\mathrm{CO})_{3}\left(\mathrm{pz}^{*} \mathrm{H}\right)(\mathrm{pypzH})\right] \mathrm{OTf}($ Scheme $1 ;$ pypzH $=2$ -

\section{Scheme 1. Compounds Herein Described ${ }^{a}$}

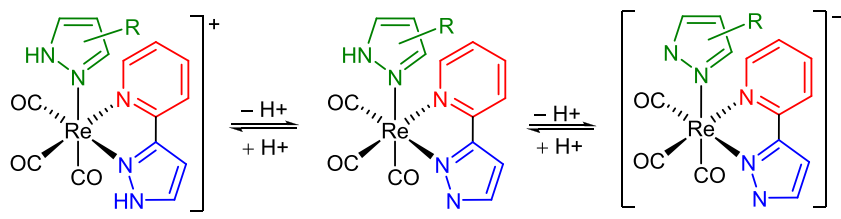

${ }_{\mathrm{pz}} * \mathrm{H}=\mathrm{pzH}, \mathrm{dmpzH}$, indzH, and pypzH.

pyridyl-3-pyrazole; pz*H = pyrazole, pzH; 3,5-dimethylpyrazole, dmpzH; indazole, indzH; or pypzH) and of the complexes obtained after their sucessive deprotonations: neutral $f a c-\left[\operatorname{Re}(\mathrm{CO})_{3}\left(\mathrm{pz}^{*} \mathrm{H}\right)(\mathrm{pypz})\right]$ and anionic $\mathrm{Na}[\mathrm{fac}$ $\left.\operatorname{Re}(\mathrm{CO})_{3}\left(\mathrm{pz}^{*}\right)(\mathrm{pypz})\right]$ (Scheme 1). Their luminescence and their electrochemistry is herein described and compared to those of other complexes closely related which have been previously reported, such as the parent complex which contains a bromido and $\mathrm{pypzH}^{15}$ or those containing bipy as diimine ligand and other pyrazolates as "sixth" ligand. ${ }^{16}$

As indicated above, one of the more attractive applications of this type of complexes is their role as catalysts for photochemical $\mathrm{CO}_{2}$ reduction, since it is related to probably the most important worldwide issues, such as global warming and the shortage of fossil-fuel resources. ${ }^{6}$ Nowadays, it is widely accepted that the incorporation of a proton source in the substrate facilitates the catalytic process via intramolecular hydrogen bonding interactions that may eventually alter the reaction products and therefore tuning of the selectivity of the reaction. Although the concept of local proton source was first applied in iron porphyrins, ${ }^{17}$ several recent reports describe reductions of $\mathrm{CO}_{2}$ catalyzed by rhenium(I) tricarbonyl diimine complexes with ligands containing different proton sources. ${ }^{18}$ This led us to explore the catalytic activity toward $\mathrm{CO}_{2}$ reduction of the complexes herein described.

\section{DISCUSSION AND RESULTS}

Syntheses and Characterization of the Complexes. The reaction of $f a c-\left[\operatorname{ReBr}(\mathrm{CO})_{3}(\right.$ pypzH $\left.)\right](\mathbf{1})^{19}$ with a slight excess of $\operatorname{AgOTf}\left(\mathrm{OTf}=\mathrm{O}_{3} \mathrm{SCF}_{3}\right)$ leads to the precipitation of $\mathrm{AgBr}$ and to $f a c-\left[\operatorname{Re}(\mathrm{OTf})(\mathrm{CO})_{3}(\mathrm{pypzH})\right](2)$, which results from the substitution of the bromido ligand by the more labile triflato (Scheme 2). The reaction occurs in THF, so the presence in solution of $f a c-\left[\operatorname{Re}(\mathrm{THF})(\mathrm{CO})_{3}(\mathrm{pypzH})\right](\mathrm{OTf})$ can not be discarded (see the Experimental Section). The triflato (or THF) ligand is then substituted by different pyrazoles $(\mathrm{pzH}, \mathrm{dmpzH}$, indzH, or pypzH), so cationic pyrazole complexes $f a c-\left[\operatorname{Re}(\mathrm{CO})_{3}\left(\mathrm{pz}^{*} \mathrm{H}\right)(\mathrm{pypzH})\right] \mathrm{OTf}$ (3) $\left(\mathrm{pz}^{*} \mathrm{H}=\mathrm{pzH}, \mathbf{3 a}\right.$; dmpzH, 3b; indzH, 3c; pypzH, 3d) are obtained after $24 \mathrm{~h}$ at $40{ }^{\circ} \mathrm{C}$.
Scheme 2. Syntheses of the Complexes

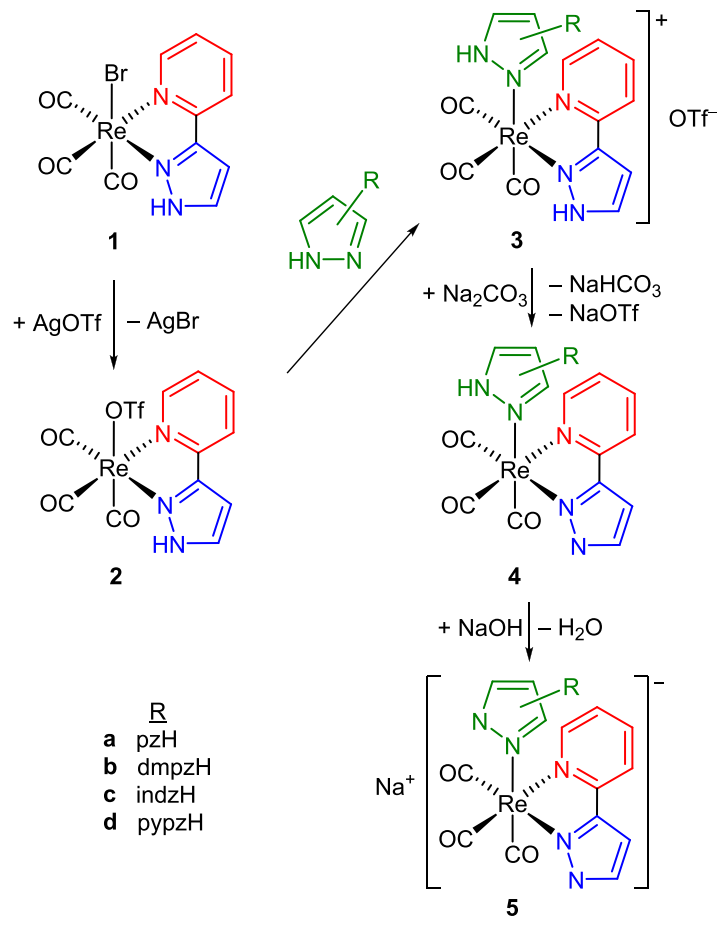

The NH protons of the pyrazole and of the pypzH ligands are acidic, so one of them can be easily removed by treatment with $\mathrm{Na}_{2} \mathrm{CO}_{3}$. These reactions afford neutral complexes fac$\left[\operatorname{Re}(\mathrm{CO})_{3}\left(\mathrm{pz}^{*} \mathrm{H}\right)(\mathrm{pypz})\right](\mathbf{4})\left(\mathrm{pz}^{*} \mathrm{H}=\mathrm{pzH}, \mathbf{4 a} ; \mathrm{dmpzH}, \mathbf{4 b}\right.$; indzH, 4c; pypzH, 4d; Scheme 2). The proposal of a deprotonated pypz and a protonated pyrazole in complexes $\mathbf{4 a}-\mathbf{d}$ is based in the crystal structure of $\mathbf{4 a}$ (see below). However, in solution this proton might be delocalized among both nitrogen donor atoms of the pyrazolate and pypz groups, as discussed below.

Deprotonation of the remaining proton requires a stronger base, and the anionic complexes $\mathrm{Na}\left[\mathrm{fac}-\mathrm{Re}(\mathrm{CO})_{3}\left(\mathrm{pz}^{*}\right)(\mathrm{pypz})\right]$ (5) $\left(\mathrm{pz}^{*}=\mathrm{pz}\right.$, 5a; dmpz, 5b; indz, 5c; pypz, 5d; Scheme 2) are obtained in solution after reaction of $4 a-d$ with the equimolar amount of aqueous $\mathrm{NaOH}$. Complex $5 \mathbf{d}$ had been previously synthesized by an alternative method, and was then completely characterized. ${ }^{19}$ All the attempts to isolate the rest of anionic complexes $\mathbf{5 a}-\mathbf{c}$ were unsuccessful, due to their high instability both in the solid state and in solution. The presence of an extra nitrogen donor atom in $\mathbf{5 d}$ (Figure 1) might explain the higher stability of this complex. In fact, similar manganese(I) complexes of formula $\left[\left\{\text { fac- } \mathrm{Mn}(\mathrm{CO})_{3}\left(\mu^{2} \text {-pypz }\right)(\mu \text {-pypz }) \mathrm{M}\right\}_{n}\right]$ $(\mathrm{M}=\mathrm{Li}, n=1 ; \mathrm{M}=\mathrm{Na}$ and $\mathrm{K} ; n=2)$ could be also
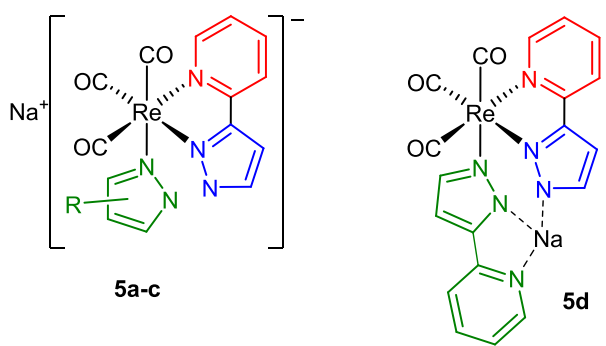

Figure 1. Complexes $\mathrm{Na}\left[f a c-\operatorname{Re}(\mathrm{CO})_{3}\left(\mathrm{pz}^{*}\right)(\mathrm{pypz})\right]\left(\mathrm{pz}^{*}=\mathrm{pz}, \mathbf{5 a}\right.$; dmpz, 5b; indz, 5c; pypz, 5d). 

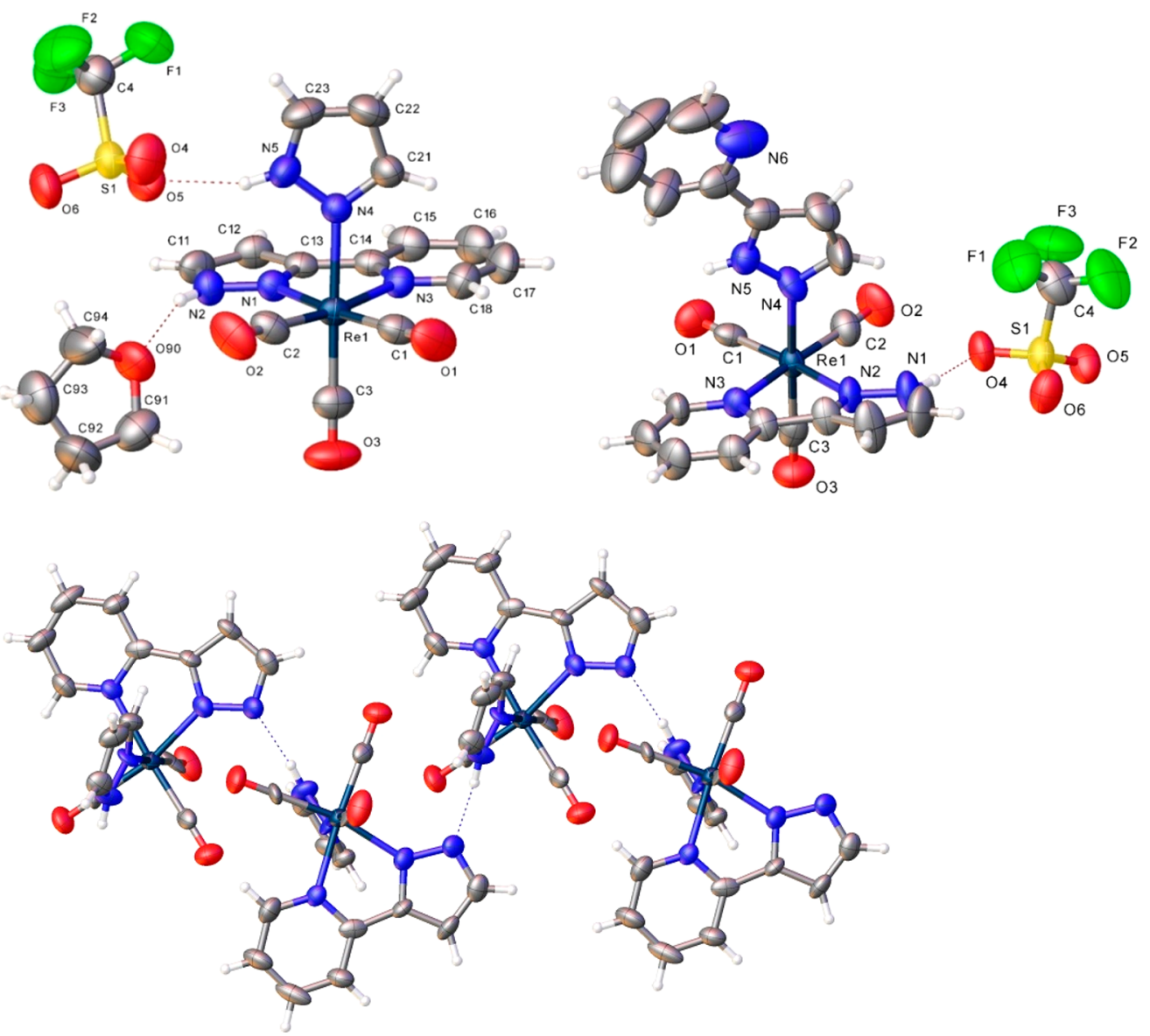

Figure 2. Perspective views of 3a (above, left), $\mathbf{3 d}$ (above, right), and $4 \mathrm{a}$ (below). Thermal ellipsoids are drawn at $30 \%$ probability.

Table 1. Absorption and Emission Data of Complexes in $\mathrm{CHCl}_{3}$ at $298 \mathrm{~K}^{a}$

\begin{tabular}{|c|c|c|c|c|c|c|}
\hline \multirow[b]{2}{*}{ comp } & \multirow{2}{*}{$\frac{\text { absorption }}{\lambda, \mathrm{nm}\left(\varepsilon \times 10^{-3}, \mathrm{M}^{-1} \mathrm{~cm}^{-1}\right)}$} & \multicolumn{5}{|c|}{ emission } \\
\hline & & $\overline{\lambda_{\text {em }}, \mathrm{nm}\left[\lambda_{\text {excit }}=360 \mathrm{~nm}\right]}$ & $\varnothing( \pm 8 \%) \times 10^{-2 b}$ & $\tau, \mathrm{ns}$ & $k_{\mathrm{r}} \times 10^{5}, \mathrm{~s}^{-1}$ & $k_{\mathrm{nr}} \times 10^{5}, \mathrm{~s}^{-1}$ \\
\hline $\mathbf{1}^{15}$ & $271(25.0), 352(2.5)$ & 519 & 5.0 & 188 & 26.5 & 504.9 \\
\hline $3 \mathbf{a}$ & $267 \mathrm{sh}(12.1), 290(8.7), 335(3.2)$ & 497 & $43(6.6)$ & 392 & 11.0 & 14.5 \\
\hline $3 \mathbf{b}$ & $252 \operatorname{sh}(8.2), 297(2.8), 366(0.2)$ & 497 & $3.1(0.3)$ & 341 & 0.9 & 28.4 \\
\hline $3 c$ & 268 (21.8), 287 sh (15.9), 300 sh (11.9), 352 (2.8) & 494 & $21(4.5)$ & 490 & 4.3 & 16.1 \\
\hline $3 \mathrm{~d}$ & $266 \mathrm{sh}(18.6), 283(19.4), 360(2.3)$ & 499 & $58(14)$ & 610 & 9.5 & 6.9 \\
\hline $4 a$ & 256 (13.1), $296(8.0), 324(4.9), 355 \mathrm{sh}(2.8)$ & 504 & $17(4.4)$ & 696 & 2.4 & 11.9 \\
\hline $4 b$ & 259 (10.4), $273 \mathrm{sh}(8.8), 298$ (5.2), 359 (1.9) & 502 & $11(1.1)$ & 281 & 3.9 & 31.7 \\
\hline $4 c$ & 269 (20.8), 289 sh (14.6), $299 \mathrm{sh}(10.8), 364 \mathrm{sh}(1.3)$ & 495 & $23(4)$ & 869 & 2.6 & 8.9 \\
\hline $4 d$ & 276 (20.1), $295 \mathrm{sh}(17.7), 318 \mathrm{sh}(11.1), 350 \mathrm{sh}(4.1)$ & 501 & $31(7.4)$ & 591 & 5.2 & 11.7 \\
\hline $5 d$ & $236(7.2), 313(6.9)$ & 508 & $2.6(0.8)$ & 220 & 1.2 & 44.5 \\
\hline
\end{tabular}

crystallographically characterized. ${ }^{19}$ Therefore, complexes $\mathbf{5 a -}$ c are herein characterized by ${ }^{1} \mathrm{H}$ NMR and IR in solution after deprotonation of corresponding cationic or neutral complexes $3 \mathbf{a}-\mathbf{c}$ or $4 \mathbf{a}-\mathbf{c}$ (see the Experimental Section).

Complexes 3a, 3d, and $4 \mathbf{a}$ have been characterized crystallographically. The crystal structures are displayed in Figure 2, and distances and angles are included in CCDC records 1971286-1971288. As expected, rhenium shows an octahedral coordination in all the structures, and the distances and angles are similar to those found in the crystal structures of other pypzR rhenium(I) tricarbonyl complexes. ${ }^{20}$ The acidic proton of the pyrazolyl unit in neutral complex $\mathbf{4 a}$ was localized in the pyrazole, and it is involved in hydrogen bonding with the deprotonated nitrogen of the pypz moiety (Figure 2, below, right). In the structures of cationic complexes 3a and 3d, the N-bound hydrogens of the pyrazoles or pypzH ligands are also involved in hydrogen bonding with molecules of solvent present in the crystals or with the anion. The distances $\mathrm{N}-\mathrm{H} \cdots \mathrm{E}(\mathrm{E}=$ heteroatom $), \mathrm{N} \cdots \mathrm{E}$, and the angles $\mathrm{N}-\mathrm{H} \cdots \mathrm{E}$ are in accordance with "weak" or "moderate" hydrogen bonds. ${ }^{21}$

The spectroscopic and analytical data are included in the Experimental Section and support the proposed geometries. The only acidic proton present in neutral complexes $\mathbf{4 a - d}$ is very probably involved in a fast exchange equilibrium between both basic nitrogen atoms in both pyrazolyl groups, as it could 
only be detected as a broad signal in the ${ }^{1} \mathrm{H}$ NMR of $\mathrm{dmpzH}$ complex $\mathbf{4 b}$ (see the Experimental Section), whereas it is too broad to be detected for the rest of neutral complexes. This fact might be related with the higher basicity of dmpz compared to that of the other pyrazolates herein employed, ${ }^{22}$ what might explain the larger energetic difference between the dmpzH-pypz and dmpz-pypzH tautomers compared to those where the rest of pyrazolyl groups are involved.

The protonation/deprotonation equilibria among the cationic $(3 \mathbf{a}-\mathbf{d})$, neutral $(\mathbf{4 a}-\mathbf{d})$, and anionic $(5 \mathbf{a}-\mathbf{d})$ species were revealed to be fast, since mixtures of them give always averaged spectra. The variation of the chemical shifts for mixtures containing different species was determined as a function of the amount of hydroxide anion added to a solution of $\mathbf{3 b}$, that allowed us to obtain successively $\mathbf{4} \mathbf{b}$ and $\mathbf{5 b}$ (Figure S1).

The IR spectra of all the complexes show three bands in the $\mathrm{C}-\mathrm{O}$ stretching region in solution (two absorptions in the solid state spectra), as expected for their fac-tricarbonyl geometries. The frequencies sequence follows the predicted trend: cationic $(3)>$ neutral $(4)$ complexes (average $\Delta \nu_{(\mathrm{CO})}=$ $\left.15-19 \mathrm{~cm}^{-1}\right)$, considering the increase of $\pi$-back-donation to the CO ligands with the enhancement of the electronic density at the metal when the positive neat electronic charge of the complex decreases.

Photophysical Studies. The main absorption and emission spectral data for complexes $3 \mathbf{a}-\mathbf{d}, \mathbf{4 a}-\mathbf{d}$, and $\mathbf{5 d}$ are summarized in Table 1 . The absorption and emission spectra, as well as the wavelengths maxima detected in different deaerated solvents at $298 \mathrm{~K}$ are collected in Figure S2. All the complexes display intense absorption bands in the 250-300 $\mathrm{nm}$ region which may be attributed to $\pi(\mathrm{L}) \rightarrow \pi^{*}(\mathrm{~L}) \mathrm{IL}$, and lower energy broad bands in the near UV region, above 300 $\mathrm{nm}$, corresponding to $\mathrm{d} \pi(\mathrm{Re}) \rightarrow \pi^{*}(\mathrm{~L})$ MLCT. The different nature of the absorptions is confirmed by the solvatochromic nature of the MLCT absorptions, where larger electric dipole changes are associated with the electronic transitions. Thus, 15 $\mathrm{nm}$ to even $60 \mathrm{~nm}$ blueshifts are observed in the MLCT bands when going from less polar $\mathrm{CHCl}_{3}$ to more polar $\mathrm{MeCN}$ (Figure S2). Meanwhile, the transitions assigned to IL $\pi-\pi^{*}$ are associated with minimal electric dipole changes and therefore are almost insensitive to the solvent change. These assignments are based on the absorption spectra of closely related metal complexes, which display similar bands, such as 271 and $352 \mathrm{~nm}$ for 1 in $\mathrm{CHCl}_{3}$. ${ }^{15}$ The similar high-energy MLCT transitions displayed by $\mathbf{1}$ and $\mathbf{3 a}-\mathbf{d}$ or $\mathbf{4 a}-\mathbf{d}$ (ca. 355 $\mathrm{nm}$, see Table 1) indicates that the replacement of a bromido ligand in $\mathbf{1}$ by different pyrazoles (complexes $\mathbf{3 a - d}$ ) does not seem to affect the $d \pi(R e)$ orbital energy. In contrast, no significative variations are observed when comparing the absorption spectra maxima of each neutral with the corresponding cationic complex (each of complexes $3 \mathbf{a}-\mathbf{d}$ vs each of $\mathbf{4 a - d}$ ), as previously reported for the deprotonation of a $\operatorname{Re}(\mathrm{I})$ complex containing 2 -( $2^{\prime}$-pyridyl)benzimidazole as chelating ligand. ${ }^{11}$ This contrasts with the deprotonation of $4 \mathrm{~d}$ to afford 5d, which occurs with a hypsochromic shift (ca. 40 $\mathrm{nm}$ ), as previously described for the deprotonation of different $\operatorname{Re}^{\mathrm{I}}(\mathrm{CO})_{3}$ complexes containing 5-aryl tetrazoles, coordinated as "sixth" ligand. ${ }^{12 b}$

Some of the complexes were also studied theoretically by means of density functional and time-dependent density functional theory (TD-DFT) calculations. Computational details can be found in the Experimental section, and the complete list of results is included in the Supporting Information. The ground-state geometries were optimized at the PBE1PBE level (PBE0) with no symmetry restraints for the complexes studied and the minimum obtained compares well with both crystal structures obtained by X-ray diffraction. As shown in Figure 3, the calculations results are consistent

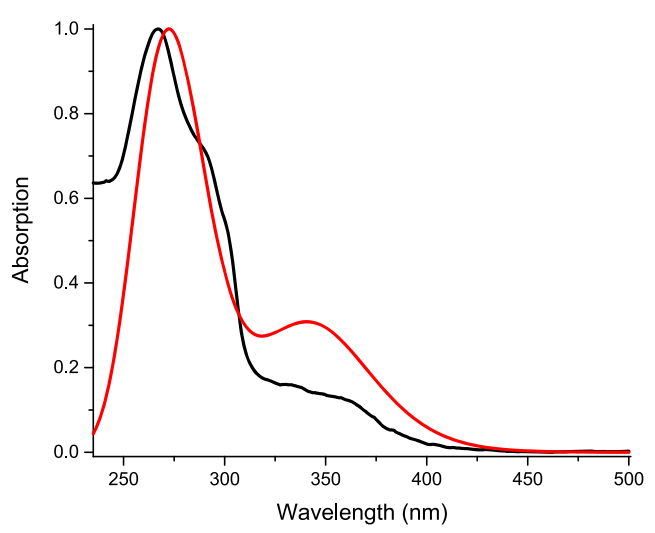

Figure 3. Calculated (red) and experimental (black) absorption spectra for $3 c$.

with the band shapes of the optical spectra of $3 c$. In order to compare analogous cationic and neutral complexes, frontier molecular orbital calculations in the ground state at the PBE1PBE level for complexes $\mathbf{3 a}$ and $\mathbf{4 a}$ (Tables S1 and S2) confirm that the HOMO-LUMO energy gap is very similar for both complexes (3.800 eV for 3a vs $3.998 \mathrm{eV}$ for $4 \mathrm{a}$ ). However, the relative contribution of the orbitals differs: The HOMO of $3 a$ has a mixed $\mathrm{Re} / \mathrm{CO} / \mathrm{pzH}(58.3 / 23.4 / 13.8)$ character, whereas that of $4 \mathbf{a}$ has a mixed $\mathrm{Re} / \mathrm{CO} / \mathrm{pypzH}$ (38.7/19.0/38.1) character. The LUMOs are localized almost exclusively on the pypz fragment, with a higher contribution from the pyridine ring, especially in neutral $4 \mathrm{a}$ ( $\mathrm{py} / \mathrm{pz}=58.4$ / 32.9 for $3 \mathrm{a}, \mathrm{py} / \mathrm{pz}=76.0 / 14.8$ for $\mathbf{4 a})$. We have been able to find only one precedent of such a different contribution between both rings of a diimine ligand, specifically in pyridyltriazolato ligands. ${ }^{23}$

The emission spectra of all the complexes show one unstructured broad band, which is solvent-dependent (3-16 $\mathrm{nm}$ shifts for $3 \mathbf{a}-\mathbf{d}, 14-41 \mathrm{~nm}$ shifts for $4 \mathbf{a}-\mathbf{d}, 33 \mathrm{~nm}$ shift for 5d). The intensities in the emission spectra of all the complexes show a dramatic increase in deaerated solutions compared to those prepared without exclusion of air, with no variation in the emission maxima (see Figure S2). These results, along with luminiscence emission lifetimes (see below), are characteristic features of ${ }^{3} \mathrm{MLCT}$ phosphorescent emissions. $^{2}$ Deprotonation of complexes $3 \mathbf{a}-\mathbf{d}$ to afford corresponding $\mathbf{4 a}-\mathbf{d}$ and further deprotonation of $\mathbf{4 d}$ to obtain anionic 5d take place with a slight bathochromic shift of the emission band (1-7 nm). This contrasts with previous reports of deprotonation of different $\mathrm{NH}$ groups present in the ligands, where blueshifts $(48 \mathrm{~nm})$ are detected when deprotonation occurs in the diimine ligands, ${ }^{11}$ whereas deprotonation in the "sixth" ligand induced redshift $(50-58 \mathrm{~nm})$ of the emission bands. ${ }^{12}$

The absolute quantum yields, measured in deaerated solutions, of $\mathbf{3 a}-\mathbf{d}, \mathbf{4 a}-\mathbf{d}$, and $\mathbf{5 d}$ are similar to those previously reported for other rhenium(I) tricarbonyl complexes containing azolates as "sixth" ligands, ${ }^{16,24}$ or azolyl fragments in the diimine ligand. ${ }^{15,20 b, 23,25}$ The comparison 
among the quantum yields of cationic complexes $3 \mathbf{a}-\mathbf{d}$ with those of their corresponding deprotonated neutral complexes $\mathbf{4 a}-\mathbf{d}$ and also with that of anionic $\mathbf{5 d}$ leads to significative variations for the $\mathrm{pz}(0.43$ for $3 \mathrm{a}$ vs 0.17 for $4 \mathbf{a})$ and pypz ( 0.59 for $3 \mathrm{~d}, 0.31$ for $4 \mathrm{~d}$ and 0.026 for $5 \mathrm{~d}$ ) complexes. Similar decreases were observed for similar deprotonations occurred in complexes containing $\mathrm{NH}$ groups in either the "sixth" ${ }^{26}$ or in the diimine ligands. ${ }^{1,12 b}$ As described above for the emission absorptions, the absolute quantum yields of all the complexes also show a dramatic decrease in aerated solutions, compared to those prepared with rigurous exclusion of air (Table 1). These results confirm the phosphorescent nature of the ${ }^{3}$ MLCT transition. ${ }^{2}$

Finally, the luminescent emission lifetimes are in the range of those previously reported for similar Re complexes. ${ }^{16,23,24,25 d}$ As previously reported for similar systems able to undergo acid-base processes, no relevant variations of emission lifetimes are observed depending on whether the complex is cationic, neutral or anionic. ${ }^{11,12 b, 26}$

In summary, all the complexes herein described display a very similar photophysical behavior, showing only slight differences when the pyrazole coordinated in the "sixth" ligand changes, or when protonation/deprotonation occurs. Theoretical calculations indicate that the HOMO-LUMO energy gap does not change with deprotonation, even though the relative contribution of the orbitals in the neutral and in the cation compound significantly differs.

Electrochemical Studies. The cyclic voltammetries (CVs) of complexes $\mathbf{1}, \mathbf{3 a}-\mathbf{d}, \mathbf{4 a}-\mathbf{d}$, and $\mathbf{5 d}$ show an electrochemical behavior consistent with $\mathrm{CO}_{2}$ activation, i.e., electrocatalyzed reduction (see Figures S3-S17). As a representative example, the results registered for complex $3 \mathrm{c}$ are shown in Figure 4.

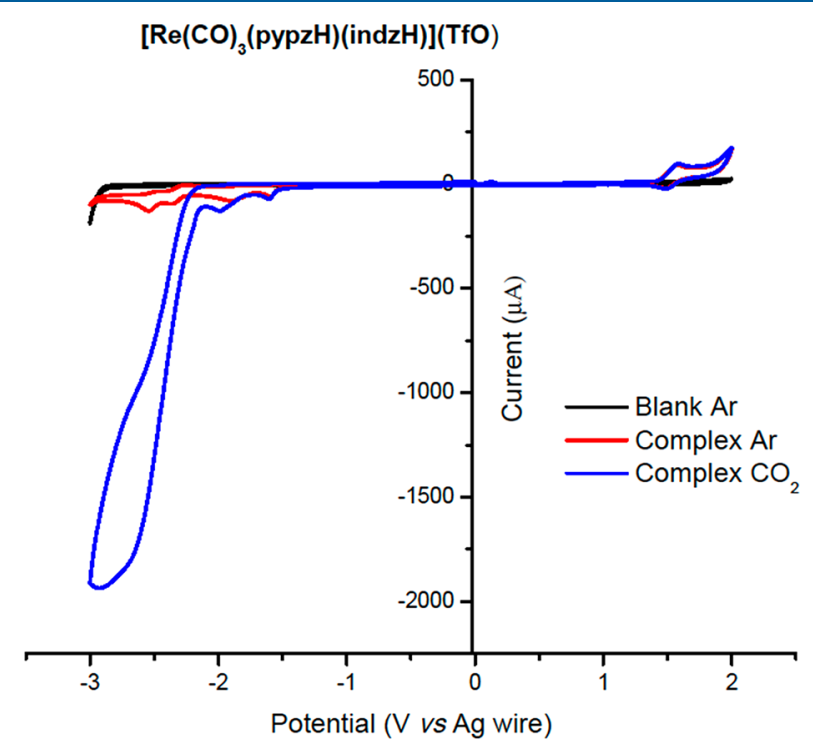

Figure 4. Cyclic voltammograms of $f a c-\left[\operatorname{Re}(\mathrm{CO})_{3}(\mathrm{pypzH})(\mathrm{indzH}]\right.$ (TfO) (3c) under Ar (red trace) and under $\mathrm{CO}_{2}$ (blue trace). See the Supporting Information and the Experimental Section for details.

Blue (corresponding to the experiment performed in $\mathrm{CO}_{2}$ atmosphere) and red (experiment performed in $\mathrm{Ar}$ atmosphere) traces overlap completely in the range of -1.5 to +2.0 $\mathrm{V}$. The black trace corresponds to the window of the blank, i.e., the solvent plus the supporting electrolyte. Changing the atmosphere from Ar to $\mathrm{CO}_{2}$ a great enhancement of the current at potentials below $-2.0 \mathrm{~V}$ is observed.

Table 2 gathers the observed potential values referenced to the redox pair ferrocenium/ferrocene, following the IUPAC recommendations. ${ }^{27}$ The experimental raw values observed using silver wire (as pseudoreference electrode) or $\mathrm{AgCl} / \mathrm{Ag}$ (3 $\mathrm{M} \mathrm{NaCl}$ reference electrode) are collected in Tables S3 and S4. The ratio $\frac{i_{\text {cat }}\left(\mathrm{CO}_{2}\right)}{i_{\text {cat }}(\mathrm{Ar})}$ ranges from 2.7 to 11.5 and allows comparison of the catalytic activity of the complexes.

For comparative and organizational purposes, in this section we first discuss the electrochemical behavior of parent bromido complex $\mathbf{1}$, followed by the discussion of neutral complexes $4 a-d$. The discussion continues with the results of the deprotonation (anionic 5d) and protonation (cationic 5a-d) process. For all the complexes, the electrochemistry under Ar atmosphere is discussed previously to the behavior under $\mathrm{CO}_{2}$ atmosphere. Correlations between electrochemical properties and changes in electronic structures and protonation states are summarized at the end of this section.

Electrochemical Behavior of fac- $\left[\mathrm{ReCl}(\mathrm{CO})_{3}\right.$ (bipy)] and 1. The electrocatalytic reduction of $\mathrm{CO}_{2}$ by $\mathrm{fac}-[\mathrm{ReCl}-$ $(\mathrm{CO})_{3}$ (bipy)] has been recognized and explored since the report by Lehn et al. in $1984 .^{28}$ It is very difficult indeed to compare the catalytic activity on the basis of overpotentials and current enhancement values reported. Such data are strongly dependent both on the working electrode and on the solvent used. Also, the dryness of the solvent is crucial. Therefore, for comparison purposes we have repeated the electrochemical measurements of $f a c-\left[\operatorname{ReCl}(\mathrm{CO})_{3}(\right.$ bipy $\left.)\right]$ under the same experimental conditions than for the complexes herein reported. The $\mathrm{CVs}$ of $\mathrm{fac}$ - $\left[\mathrm{ReCl}(\mathrm{CO})_{3}\right.$ (bipy) $]$ are depicted in Figure S3, and potentials collected in Table 2. The enhancement ratio of the cathodic currents is $\frac{i_{\text {cat }}\left(\mathrm{CO}_{2}\right)}{i_{\text {cat }}(A r)}=8.1$, and the maximum of the cathodic current was observed at $-2.86 \mathrm{~V}$ (vs $\mathrm{Fc}^{+} / \mathrm{Fc}$ ).

We have previously reported the electrochemistry of $\mathbf{1}$ under $\mathrm{N}_{2}$ at a platinum electrode using the SCE reference electrode in THF. ${ }^{19}$ Herein we report the electrochemistry at a GC (glassy carbon) electrode in dry $\mathrm{MeCN}$ using the $\mathrm{AgCl} / \mathrm{Ag}$ reference electrode. The different working electrodes and solvents used led to important differences, which supports the feasibility to make comparisons only when the experimental conditions are exactly the same. Under $\mathrm{GC} / \mathrm{MeCN}$, we observe (Figure S4 and Table S4) a one-electron irreversible oxidation at $E_{\mathrm{pk}}^{\mathrm{ox}}=1.40 \mathrm{~V}$ vs $\mathrm{AgCl} / \mathrm{Ag}(\mathrm{NaCl}, 3 \mathrm{M})(0.96 \mathrm{~V}$ vs $\left.\mathrm{Fc}^{+} / \mathrm{Fc}\right)$, followed by an apparently reversible wave at $E_{1 / 2}=$ $1.80 \mathrm{~V}$ vs $\mathrm{AgCl} / \mathrm{Ag}(\mathrm{NaCl}, 3 \mathrm{M})$. Comparable anodic scan pattern and potentials have been reported for complexes fac$\left[\operatorname{ReX}(\mathrm{CO})_{3}(\right.$ bipy $\left.)\right](\mathrm{X}=\mathrm{Cl}$ and $\mathrm{Br})$, including detailed mechanistic insights which may be applied to our complexes. ${ }^{29}$ Related complexes with different aromatic diimines generally show irreversible oxidation waves between 0.9 and $1.2 \mathrm{~V}$ vs $\mathrm{Fc}^{+} / \mathrm{Fc}^{30}$ The $\mathrm{Re}^{\mathrm{I}} / \mathrm{Re}^{\mathrm{II}}$ couple was reported to be "quasireversible" for a six-membered chelate ring diimine. ${ }^{31}$ The small peak (more prominent under $\mathrm{CO}_{2}$ ) at $+0.85 \mathrm{~V}$ (vs $\mathrm{AgCl}$ / $\mathrm{Ag}$ ) is assigned again to the presence of bromide ion. ${ }^{19}$ The role of bromine during the oxidation of related rhenium(I) tricarbonyl diimine complexes has been reported already. ${ }^{14,29}$

The electrochemistry of $\mathbf{1}$ scanning to negative reduction potentials (cathodic scan) had not been reported to date. On the basis of the electrocatalytic activity of $\mathrm{fac}$ - $[\mathrm{ReCl}$ - 
Table 2. Electrochemical Data Obtained by Cyclic Voltammetry in This Study and Referenced to the Redox System Ferrocenium/Ferrocene ${ }^{a}$

\begin{tabular}{|c|c|c|c|c|c|}
\hline \multirow[b]{2}{*}{ complex } & \multicolumn{2}{|c|}{ observed $E_{\mathrm{pk}}^{\mathrm{ox}}$ and $E_{\mathrm{pk}}^{\mathrm{red}}$ values ${ }^{b}$} & \multirow[b]{2}{*}{$i_{\text {cat }}(\mathrm{Ar})^{c}$} & \multirow[b]{2}{*}{$i_{\text {cat }}\left(\mathrm{CO}_{2}\right)^{c}$} & \multirow[b]{2}{*}{ ratio $^{d} i_{\text {cat }}\left(\mathrm{CO}_{2}\right) / i_{\text {cat }}(\mathrm{Ar})$} \\
\hline & anodic scan & cathodic scan & & & \\
\hline$f a c-\left[\operatorname{ReCl}(\mathrm{CO})_{3}(\right.$ bipy $\left.)\right]$ & & $-1.78,-2.15$ & -24 & -195 & 8.1 \\
\hline 1 & $0.41,^{e} 0.96,1.36^{f}$ & $-2.04,-2,14$ & -133 & -953 & 7.2 \\
\hline $3 a$ & $1.21^{f}$ & $-1.94,-2.30,-2.74,-2.89$ & -200 & -1300 & 6.5 \\
\hline $3 b$ & $1.19^{f}$ & $-1.15,-2.30,-2.75$ & -166 & -1400 & 8.4 \\
\hline $3 c$ & $1.26^{f}$ & $-1.87,-2.18,-2.64,-2.81$ & -168 & -1935 & 11.5 \\
\hline $3 d$ & $1.12(\mathrm{sh}),^{g} 1.29$ & $-2.10,-2.65$ & -94 & -800 & 8.5 \\
\hline $4 a$ & $0.70,1.19^{f}$ & $-2.63,-2.93$ & -57 & -490 & 8.6 \\
\hline $4 b$ & $0.67,1.10^{f}$ & $-2.40,-2.74,-2.98$ & -114 & -303 & 2.7 \\
\hline $4 c$ & $0,74,1.26^{f}$ & $-2.20,-2.64$ & -52 & -590 & 11.3 \\
\hline $4 d$ & $0.39,0.61,1.08^{f}$ & -2.72 & -58 & -562 & 9.7 \\
\hline $5 d$ & $0.34,0.54,0.96^{f}$ & -2.77 & -55 & -311 & 5.6 \\
\hline
\end{tabular}

${ }^{a_{T}}$ The reduction potential mean value observed for ferrocenium/ferrocene $\left(\mathrm{Fc}^{+} / \mathrm{Fc}\right)$ used as internal calibrant under the employed experimental conditions was $E^{\circ}=0.443 \pm 0.005 \mathrm{~V}$ vs the $\mathrm{AgCl} / \mathrm{Ag}(3 \mathrm{M} \mathrm{NaCl})$ electrode (see values at Table S4). ${ }^{b}$ Anodic or cathodic scan peaks observed under Ar unless stated otherwise. ${ }^{c}$ Maximum registered cathodic current $(\mu \mathrm{A})$ under $\mathrm{Ar}, i_{\text {cat }}(\mathrm{Ar})$, or under $\mathrm{CO}_{2}, i_{\text {cat }}\left(\mathrm{CO}_{2}\right)$. ${ }^{d}$ Ratio between the Faradaic currents observed under $\mathrm{Ar}, i_{\text {cat }}(\mathrm{Ar})$, or under $\mathrm{CO}_{2}, i_{\text {cat }}\left(\mathrm{CO}_{2}\right)$. ${ }^{e}$ Assigned to bromide earlier for the analogous fac$\left[\mathrm{MnBr}(\mathrm{CO})_{3}(\mathrm{pypzH})\right] .{ }^{19}$ This peak appears in the reverse of the cyclic scan from $0 \mathrm{~V}$ to $+2 \mathrm{~V}$ to $0 \mathrm{~V}$ (see Figure S4). ${ }_{\mathrm{W}}$ Waves where both peaks $i_{\text {ox }}$ and $i_{\text {red }}$ were observed. Value of $E_{1 / 2}$ is given in those cases. ${ }^{g}$ Shoulder, not resolved peak (see Figure S12).

$(\mathrm{CO})_{3}$ (bipy)] for the reduction of $\mathrm{CO}_{2}$ and its structural and electronic similarity with 1 , we decided to explore its electrochemical behavior both under argon and under carbon dioxide, which led to our observation of a 5-fold current enhancement at $-2 \mathrm{~V}$ (see Figure S4) for the latter. This experiment points to the need for scanning to more negative potentials $(<-2 \mathrm{~V})$. Therefore, CVs of 1 were recorded in the range of +1 to $-3 \mathrm{~V}$ (see Figure S5). In order to avoid adventitious undesired water from the $\mathrm{AgCl} / \mathrm{Ag}(3 \mathrm{M} \mathrm{NaCl})$ reference electrode, a silver wire was used as pseudoreference electrode, and ferrocene was added at the end of the measurements as internal calibrant. As displayed in Figure S5 (red trace), scanning to negative potentials under Ar led to several waves indicating that the complex undergoes successive electron transfer reductions. Repeating the same scan under $\mathrm{CO}_{2}$ leads to intense enhancement of the cathodic current. The maximum cathodic current under $\mathrm{CO}_{2}$ was found at $-2.78 \mathrm{~V}\left(\mathrm{vs} \mathrm{Fc}^{+} / \mathrm{Fc}\right)$. At this potential, the ratio of the cathodic current is $\frac{i_{\text {cat }}\left(\mathrm{CO}_{2}\right)}{i_{\text {cat }}(\mathrm{Ar})}=7.2$. According to these experimental results, the electrocatalytic activity of complexes $\mathrm{fac}$-[ReCl$(\mathrm{CO})_{3}$ (bipy)] and $\mathbf{1}$ are quite similar. The different shapes of the waves associated to electrocatalytic reduction of $\mathrm{CO}_{2}$ come from the competition at the electrode surface between $\mathrm{CO}_{2}$ consumption (related to the rate-determinant step of the catalytic cycle) and the arrival of new substrate by diffusion. ${ }^{6 c}$

Electrochemical Behavior of Neutral Complexes $4 a-d$. Neutral complexes $\mathbf{4 a - d}$ are discussed first because they formally result from the substitution of the bromido anionic ligand in complex $\mathbf{1}$ by different pyrazolates, even though the remaining acidic proton is formally bonded to the pyrazole, as discussed above. In all the complexes the first oxidation peak (related to the HOMO) is shifted to less positive potentials, indicating that the couple pyridylpyrazolate-pyrazole is a better donor than the pyridylpyrazole-bromido pair. This is confirmed by the IR $\nu_{\mathrm{CO}}$ wavenumbers $\left(\nu_{\mathrm{CO}}\right.$ average 1944.7-1946.7 $\mathrm{cm}^{-1}$ for $\mathbf{4 a - d}$ vs 1950.7 for $\mathbf{1},{ }^{19}$ in THF).

Under Ar, neutral complexes $\mathbf{4 a}-\mathbf{d}$ have a common pattern similar to that of $\mathbf{1}$ in the anodic scan to positive potentials. It consists of one irreversible peak in the range $0.61-0.96 \mathrm{~V}$, followed by a second reversible wave in the range 1.08-1.36 V. A similar behavior has been previously reported for analogous $\left[\mathrm{ReX}(\mathrm{CO})_{3}\right.$ (diimine $\left.)\right](\mathrm{X}=\mathrm{Cl}$ and $\mathrm{Br})$ complexes, as well as a mechanistic proposal. ${ }^{29}$ As discussed below, the oxidation of cationic complexes $\mathbf{3 a}-\mathbf{d}$ occurs, as expected by simple Coulombic considerations, to more positive potentials.

The values of the peak potentials observed at cathodic scans (under Ar) seem quite erratic. The change of bromidopyridylpyrazole (neutral complex 1) by pyrazole-pyridylpyrazolate (neutral complexes $\mathbf{4 a - d}$ ) renders reduction more difficult (more negative potential values observed).

For complex $4 \mathbf{a}$, the observed anodic scan pattern (see Figure S13) reproduces that observed for $\mathbf{1}$ but shifted to lower potentials (see Table 2), as pointed out in the precedent paragraph. A small peak sometimes detected on oxidative scans, at ca. $+0.2 \mathrm{~V}$, may be attributed to coatings of the working electrode formed when very negative potentials have been previously reached, being cleaned in the following scan to positive potentials. Table 2 shows that more negative potentials are needed to reduce $\mathbf{4 a}$ compared to $\mathbf{1}$, which would indicate that pyrazolate ligand destabilizes the LUMO. The cathodic current enhancement is $\frac{i_{\text {cat }}\left(\mathrm{CO}_{2}\right)}{i_{\text {cat }}(\mathrm{Ar})}=8.6$.

Under anodic scan to positive potentials, $\mathbf{4 b}$ repeats the same pattern as the analogous unmethylated 4 a (Figure S14). However, the observed potentials shift to more positive values under $\mathrm{CO}_{2}$ atmosphere (green trace in Figure S14), suggesting that $\mathrm{CO}_{2}$ modifies the chemical steps that follow the first electron transfer. The maximum cathodic current under $\mathrm{CO}_{2}$ is found at $-3.09 \mathrm{~V}\left(\mathrm{vs}^{\mathrm{Fc}} / \mathrm{Fc}\right)$, and the ratio of the cathodic currents is $\frac{i_{\text {cat }}\left(\mathrm{CO}_{2}\right)}{i_{\text {cat }}(\mathrm{Ar})}=2.7$, the lowest for all the complexes herein described.

For complex 4c, the anodic scan reproduces previous patterns (see Figure S15). No shifts are observed when changing from Ar to $\mathrm{CO}_{2}$. The maximum cathodic current under $\mathrm{CO}_{2}$ is found at $-3.03 \mathrm{~V}\left(\mathrm{vs} \mathrm{Fc}^{+} / \mathrm{Fc}\right)$, and the ratio of the cathodic currents is $\frac{i_{\text {cat }}\left(\mathrm{CO}_{2}\right)}{i_{\text {cat }}(\mathrm{Ar})}=11.3$, the highest of the neutral complexes herein described. 
The anodic scan of $\mathbf{4 d}$, shown in Figure S16, deserves some comment, since an additional irreversible wave appears at lower potential (see also Table 2). The origin of this new wave with an $E_{\mathrm{pk}}^{\mathrm{ox}}=0.39 \mathrm{~V}\left(\mathrm{vs} \mathrm{Fc}^{+} / \mathrm{Fc}\right)$ may be associated to the possibility of a higher proton-resonance effect between the protonated and deprotonated pypz ligands. In fact, in this complex the remaining proton may be delocalized among three nitrogen donor atoms, instead of two nitrogen atoms for the remaining neutral complexes, $\mathbf{4 a}-\mathbf{c}$. The maximum cathodic current under $\mathrm{CO}_{2}$ is found for $4 \mathrm{~d}$ at $-3.03 \mathrm{~V}\left(\mathrm{vs} \mathrm{Fc}^{+} / \mathrm{Fc}\right)$, and the ratio of the cathodic currents is $\frac{i_{\mathrm{CO}_{2}}}{i_{\mathrm{Ar}}}=9.7$ at this potential.

Electrochemical Behavior of Anionic Complex 5d. As for $\mathbf{1}$, the electrochemistry of $\mathbf{5 d}$ under $\mathrm{N}_{2}$ at a platinum electrode using the SCE reference electrode in THF has been previously studied, ${ }^{19}$ whereas herein is included the electrochemistry at a $\mathrm{GC}$ (glassy carbon) electrode in dry $\mathrm{MeCN}$ using the $\mathrm{AgCl} / \mathrm{Ag}$ reference electrode. We observe under $\mathrm{GC} / \mathrm{MeCN}$ (Figure S17 and Table S4) three one-electron irreversible oxidations at $E_{\mathrm{pk}}^{\mathrm{ox}}=0.78,0.98$, and $1.40 \mathrm{~V}$ vs $\mathrm{AgCl} / \mathrm{Ag}(3 \mathrm{M} \mathrm{NaCl})$. A single one-electron reduction is detected when scanning to negative potentials under $\mathrm{Ar}$, and an intense enhancement of the cathodic current is observed when repeating the same scan under $\mathrm{CO}_{2}$ (Figure S17). The maximum cathodic current under $\mathrm{CO}_{2}$ is found at $-2.77 \mathrm{~V}\left(\mathrm{vs} \mathrm{Fc}^{+} / \mathrm{Fc}\right)$, and the ratio of the cathodic current is $\frac{i_{\mathrm{CO}_{2}}}{i_{\mathrm{Ar}}}=5.6$ at this potential. As shown in Table 2, the electrochemical properties of $\mathbf{5 d}$ are very similar to those of its protonated parent $4 \mathbf{d}$, although the main difference is precisely their behavior under $\mathrm{CO}_{2}$, where the ratio of the cathodic current is higher for neutral complex $4 \mathrm{~d}$ (9.7). This similarity may be explained considering the structural analogy between neutral complex $4 d$ and its deprotonated form $\mathbf{5 d}$ (Figure 5), where a covalently bonded

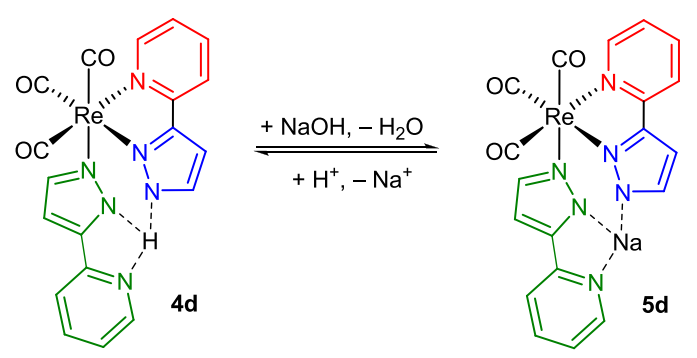

Figure 5. Complexes fac- $\left[\mathrm{Re}(\mathrm{CO})_{3}(\right.$ pypzH $\left.)(\mathrm{pypz})\right](4 \mathrm{~d})$ and $\mathrm{Na}[$ fac$\operatorname{Re}(\mathrm{CO})_{3}\left(\right.$ pypz $\left._{2}\right](\mathbf{5 d})$.

sodium atom may be proposed, according to the crystal structures of the manganese(I) complexes $\left[\left\{\right.\right.$ fac- $\mathrm{Mn}(\mathrm{CO})_{3}\left(\mu^{2}\right.$ pypz $)(\mu$-pypz $\left.)\}_{n}\right](\mathrm{M}=\mathrm{Li}, n=1 ; \mathrm{M}=\mathrm{Na}$ and $\mathrm{K} ; n=2)$, which could be crystallographically characterized. ${ }^{19}$ In fact, the main electrochemical difference between $\mathbf{4 d}$ and $\mathbf{5 d}$ is precisely their behavior under $\mathrm{CO}_{2}$, where the ratio of the cathodic current is higher for neutral complex $4 \mathbf{d}$ (9.7 vs 5.6 for $\mathbf{5 d}$ ). This is in accordance with the relevance of the presence of protons in the electrochemical reduction of $\mathrm{CO}_{2}$. The lower stability of complexes $\mathbf{5 a}-\mathbf{c}$ may be related to their prominent anionic nature, as depicted in Figure 1.

Electrochemical Behavior of Cationic Complexes $3 a-d$. For cationic pyrazole-pyridylpyrazole complexes $3 \mathbf{a}-\mathbf{d}$, the potentials shift to less negative values respect to those of neutral $\mathbf{4 a}-\mathbf{d}$, i.e., adding electrons becomes easier, as expected when the charge of the complexes changes from 0 to +1 . Two, three, or even four peaks are observed depending on the complex. Previous mechanistic studies indicate that several different species might account for the observed peaks at cathodic scans. ${ }^{6 a}$ Furthermore, deprotonation in complexes $\mathbf{3 a}-\mathbf{d}$ may add new active species, as reported previously for similar imidazole complexes. ${ }^{32}$ In spite of the random cathodic scans under argon, a parallel behavior is observed under $\mathrm{CO}_{2}$ which consists in a large enhancement of the cathodic current associated to the reduction of $\mathrm{CO}_{2}$.

Cationic complexes $3 \mathbf{a}-\mathbf{d}$ display similar results of the anodic scans. A clean and apparently reversible wave at +1.42 $\mathrm{V}$ assigned to the one-electron transfer $\operatorname{Re}(\mathrm{I})$ to $\operatorname{Re}(\mathrm{II})$ is detected for 3a, as shown in Figures S6 and S7. This wave is not affected by the change from Ar to $\mathrm{CO}_{2}$ atmosphere (the blue and red traces overlap completely), indicating a pure electron transfer reaction. The observed reversibility may be understood in terms of the proposed mechanism by Bullock et al. ${ }^{29}$ According to this mechanism, a ligand bridges two $\operatorname{Re}(\mathrm{II})$ units following the electron transfer, but cationic complexes $3 a-c$ do not contain a ligand able to bridge two metal atoms, thus avoiding the chemical step that follows the electron transfer. On the contrary, neutral complexes $\mathbf{4 a}-\mathbf{d}$ do contain an available lone pair in the pyridylpyrazolate ligand to behave as bridging ligand; thus, they follow the expected pattern. Going to reduction potentials, four peaks are observed at $-1.94,-2.30,-2.74$, and $-2.89 \mathrm{~V}(210 \mu \mathrm{A})$ under Ar. However, under $\mathrm{CO}_{2}$ only two peaks at -1.73 and $-2.09 \mathrm{~V}$ remain observable, since the peaks at more negative potentials are hidden by the catalytically enhanced current. This means that reduction of $\mathrm{CO}_{2}$ only starts when the complex has been reduced by at least two electrons. The observation that the peak of the enhanced current does not reach a plateau is another particular feature of $3 \mathbf{a}$. Such a plateau current may be unveiled at lower concentration of $\mathrm{CO}_{2}$. Figure $\mathrm{S} 7$ displays the evolution of the CVs when the concentration of $\mathrm{CO}_{2}$ is progressively reduced by bubbling Ar: Under saturated $\mathrm{CO}_{2}$, a current value of $2200 \mu \mathrm{A}$ without plateau was recorded (Figure S6), but on removing $\mathrm{CO}_{2}$ by bubbling $\mathrm{Ar}$ for $3 \mathrm{~min}$ (Figure $\mathrm{S} 7$, black trace), the current value obtained is $612 \mu \mathrm{A}$, which is reduced at $5 \mathrm{~min}$ (Figure $\mathrm{S} 7$, red trace) to $447 \mu \mathrm{A}$ and after 7 min (Figure S7, blue trace) to $262 \mu \mathrm{A}$, a value close to the current observed under $\operatorname{Ar}(210 \mu \mathrm{A}$, Figure S6). A similar experiment on $\mathbf{3 b}$ is shown in Figure S10. For $\mathbf{3 a}$, the maximum cathodic current under $\mathrm{CO}_{2}$ is found at $-3.03 \mathrm{~V}$ (vs $\left.\mathrm{Fc}^{+} / \mathrm{Fc}\right)$, and the ratio of the cathodic currents is $\frac{{ }^{i} \mathrm{CO}_{2}}{i_{\mathrm{Ar}}}=6.5$ at this potential.

For $\mathbf{3 b}$, the scan to positive potentials (Figures S8 and S9) shows a "quasi-reversible" wave at $+1.40 \mathrm{~V}$ assigned to the oneelectron transfer $\operatorname{Re}^{\mathrm{I}} \rightarrow \mathrm{Re}^{\mathrm{II}}$. This wave is not affected by the change form Ar to $\mathrm{CO}_{2}$ (the black and red traces overlap completely in Figure S9) indicating a pure electron transfer reaction.

Complex 3c shows (Figure S11) the greatest current enhancement ratio $\left(\frac{i_{\mathrm{CO}_{2}}}{i_{\mathrm{Ar}}}=11.5\right)$ for all the complexes herein reported, a value close to that shown by corresponding neutral complex 4c (11.3). This suggests that the presence of indazole ligand in the "sixth" coordination position might play a main role in the reduction mechanism of the $\mathrm{CO}_{2}$. This feature may be explained considering the acidity of the pyrazole ligand, as detailed below. 
Finally, complex 3d shows a peculiar feature at oxidative or anodic scans (Figure S12). The pattern is similar to those of neutral complexes $\mathbf{4 a}-\mathbf{c}$ discussed above. Complex $\mathbf{3 d}$ is the only cationic example with a free donor nitrogen atom able to bridge two rhenium atoms in order to follow the proposed mechanism by Bullock et al. ${ }^{29}$

Controlled Potential Electrolysis. In order to evaluate the product formed at the catalytic wave observed in the $\mathrm{CV}$ studies, we have performed controlled potential electrolysis (CPE) of complexes $3 \mathbf{a}$ and $\mathbf{4 a}$, which are representative of the series. In both cases, $\mathrm{CPE}$ was performed under $\mathrm{CO}_{2}$-saturated solution of catalyst $(1 \mathrm{mM})$ in $\mathrm{MeCN}$ with the supporting electrolyte $\left({ }^{n} \mathrm{Bu}_{4} \mathrm{PF}_{6}, 0.1 \mathrm{M}\right)$ with a glassy carbon rod as working electrode (see the Experimental Section for further details). The evolution of products was monitored on-line under a constant $\mathrm{CO}_{2}$ flow passed thought the solution. For both catalysts, the applied potential was set at the beginning of the catalytic wave, at about $-50 \mathrm{mV}$ from the onset potential, and the major product was $\mathrm{CO}$, with faradaic yields of about 61 and $89 \%$ and turnover numbers of 1 and 7 after $1 \mathrm{~h}$ for $3 \mathrm{a}$ and 4a, respectively (Figures S18 and S19).

Electrochemical Behavior: Summary. The accepted mechanism for the electrocatalytic reduction of $\mathrm{CO}_{2}$ with $\mathrm{Mn}(\mathrm{I})$ and $\operatorname{Re}(\mathrm{I})$ tricarbonyl complexes starts with the dissociation of the "sixth" ligand from the one-reducedelectron complex, generating a 17 electron species that binds $\mathrm{CO}_{2}{ }^{6}$ In our system, the "sixth" coordination position is occupied by different pyrazole ligands, therefore determining the strength of their bonds to the metal is crucial in order to explain the enhancement of the current observed for $\mathrm{CO}_{2}$ atmosphere. Thus, the energies of the different Repz $* \mathrm{H}$ bonds have been calculated both the for cationic complexes and for their one-reduced-electron species (Figure S20 and Table S5). The results indicate that the bond energies of the one-reducedelectron species (from 3.4 to $7.6 \mathrm{kcal} / \mathrm{mol}$ ) are much lower than those of the cationic complexes (from 23.9 to $25.2 \mathrm{kcal} /$ mol), supporting dissociation of the "sixth" ligand being facilitated once the complex has been reduced. However, the values obtained (Table S5) do not depend on the nature of the pyrazole, which does not explain the differences observed between the cationic compounds. This contrasts with the experimental values, since as indicated above, complexes containing indazole show the highest catalytic activity (11.5 or 11.3 for $3 \mathrm{c}$ or $4 \mathrm{c}$, respectively, versus 7.2 for related bromido complex 1, see Table 2). However, this observation might be related to the second step in the catalytic process, where the $\eta^{1}$-C-bound $\mathrm{CO}_{2}$ is activated by proton donors so that $\mathrm{C}-\mathrm{O}$ bond cleavage is facilitated. ${ }^{6 c}$ Therefore, a higher acidity of the uncoordinated pyrazole might promote this second step, and in fact the values obtained for the catalytic activity in the electrocatalytic reduction of $\mathrm{CO}_{2}$ are similar to those reported for the acidity of pyrazoles experimentally determined: indzH (13.96) > pzH (14.18) > dmpzH (15.00) ( $\mathrm{p} K_{\mathrm{a}}$ values in $\mathrm{H}_{2} \mathrm{O}$ at $25^{\circ} \mathrm{C}$; no pypzH nor 3-phenylpyrazole were included in these studies). ${ }^{22}$

In conclusion, one determining factor in order to explain the different behavior of the complexes herein described as catalysts for $\mathrm{CO}_{2}$ reduction might be related to the acidity of the pyrazoles coordinated in the "sixth" position, which after being liberated, may activate the coordinated $\mathrm{CO}_{2}$ once the first one-electron reduction occurs. The lower catalytic activity of $\mathbf{5 d}$, which is the only complex without protons, also supports this proposal. Even though the differences between the complexes behavior are not significant, a clear relationship between the acidity of the pyrazole in the "sixth" position and the $\left[i_{\text {cat }}\left(\mathrm{CO}_{2}\right) / i_{\text {cat }}(\mathrm{Ar})\right]$ ratio may be established.

\section{CONCLUSIONS}

Cationic rhenium(I) tricarbonyl complexes containing pypzH as a chelate ligand and different pyrazoles $\mathrm{pz}^{*} \mathrm{H}$ as monodentate ligands have been synthesized and successively deprotonated in order to obtain the corresponding neutral and anionic complexes. The latter are too unstable in both the solid state and solution, which precluded further study. The first deprotonation occurs formally on the pypzH ligand, even though the remaining proton is delocalized in solution among the basic nitrogen atoms of the pyrazolyl groups. The luminescent and electrochemical properties of the complexes (cationic, neutral, and one anionic) have been studied in order to determine the influence of the deprotonation process on these properties. The luminescent properties of the complexes herein described are similar to those related $f a c-\operatorname{Re}^{\mathrm{I}}(\mathrm{CO})_{3}$ species, as is their behavior in acid-base processes; in some cases significant decreases of quantum yields occur as protons are removed. The complexes are active in the electrocatalyzed reduction of $\mathrm{CO}_{2}$ to $\mathrm{CO}$, with some of the catalytic activities being higher than those reported for similar bromido complexes. In fact, the catalytic activity of the complexes herein reported might be related to the acidity of the pyrazoles coordinated in the "sixth" position.

\section{EXPERIMENTAL SECTION}

General Remarks. All manipulations were performed under a $\mathrm{N}_{2}$ atmosphere following conventional Schlenk techniques. Solvents were purified according to standard procedures. ${ }^{33}$ Compounds $\mathbf{1}^{15}$ and 5d, ${ }^{19}$ were obtained as previously described. All other reagents were obtained from the usual commercial suppliers and used as received. Infrared spectra were recorded in a PerkinElmer RX I FT-IR apparatus using $0.2 \mathrm{~mm} \mathrm{CaF}_{2}$ cells for solutions or in a Bruker Tensor 27 FTIR for solid samples. NMR spectra were recorded in a Agilent MR 400 or in a Agilent $500 \mathrm{DD} 2$ instruments in $\left(\mathrm{CD}_{3}\right)_{2} \mathrm{CO}$ at room temperature (r.t.) unless otherwise indicated and are referred to the internal residual solvent peak for ${ }^{1} \mathrm{H}$ and ${ }^{13} \mathrm{C}\{1 \mathrm{H}\}$ NMR. Assignments of the ${ }^{1} \mathrm{H}$ NMR spectra (Figure 6) were supported by COSY,

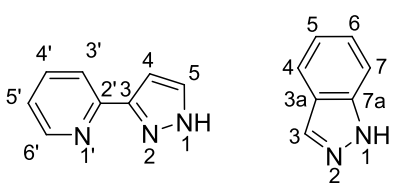

Figure 6. Numbering of pypzH and indzH for NMR assignment.

TOCSY, and NOESY experiments, and assignment of ${ }^{13} \mathrm{C}\left\{{ }^{1} \mathrm{H}\right\}$ NMR data were supported by HMBC and HSQC heteronuclear experiments. Elemental analyses were performed on a Thermo Fisher Scientific EA Flash 200.

fac- $\left[\operatorname{Re}(\mathrm{CO})_{3}(\mathrm{pzH})(\mathrm{pypzH})\right] \mathrm{OTf}, 3 \mathrm{a} . \operatorname{AgOTf}(0.152 \mathrm{~g}, 0.6 \mathrm{mmol})$ was added to a solution of $1(0.245 \mathrm{~g}, 0.5 \mathrm{mmol})$ in THF $(20 \mathrm{~mL})$; the mixture was stirred at r.t. for $1 \mathrm{~h}$ in the absence of light and then filtered to remove solid AgBr. Removal of the solvent in vacuo gave 2 as an orange oil. ${ }^{34}$ This oil was dissolved in THF $(25 \mathrm{~mL})$, and $\mathrm{pzH}$ was added $(0.034 \mathrm{~g}, 0.5 \mathrm{mmol})$. The solution was stirred at $40{ }^{\circ} \mathrm{C}$ for $24 \mathrm{~h}$. The solution was concentrated in vacuo, and $\mathrm{Et}_{2} \mathrm{O}$ was added (ca. $25 \mathrm{~mL}$ ). Cooling at $-20{ }^{\circ} \mathrm{C}$ gave a yellow microcrystalline solid, which was decanted, washed with $\mathrm{Et}_{2} \mathrm{O}(3 \times 3 \mathrm{~mL})$, and dried, yielding $0.230 \mathrm{~g}(73 \%) .{ }^{1} \mathrm{H}$ NMR $(500 \mathrm{MHz}) \delta: 6.38(\mathrm{t}, J=2.4 \mathrm{~Hz}$, $\left.H^{4} \mathrm{pzH} 1 \mathrm{H}\right), 7.25\left(\mathrm{~d}, J=2.3 \mathrm{~Hz}, H^{3,5} \mathrm{pzH}, 1 \mathrm{H}\right), 7.45(\mathrm{~d}, J=2.6 \mathrm{~Hz}$, $H^{5}$ pypzH, $\left.1 \mathrm{H}\right), 7.77$ (ddd, $J=7.3,5.5$, and $1.8 \mathrm{~Hz}, H^{5 \prime}$ pypzH, $1 \mathrm{H}$ ), 
$7.97\left(\mathrm{~d}, J=2.6 \mathrm{~Hz}, H^{5,3} \mathrm{pzH}, 1 \mathrm{H}\right), 8.31-8.53\left(\mathrm{~m}, H^{4}, H^{3 \prime}\right.$, and $H^{4 \prime}$ pypzH, 3H), $9.27\left(\mathrm{~d}, J=5.4 \mathrm{~Hz}, H^{6 \prime}\right.$ pypzH, $\left.1 \mathrm{H}\right), 12.94(\mathrm{br} \mathrm{s}, \mathrm{NH}$ pzH, 1H), 14.18 (br s, NH pypzH, $1 \mathrm{H}) .{ }^{13} \mathrm{C}\left\{{ }^{1} \mathrm{H}\right\}$ NMR $(101 \mathrm{MHz})$ $\delta: 105.7\left(\mathrm{C}^{5}\right.$ pypzH $), 107.1\left(\mathrm{C}^{4} \mathrm{pzH}\right), 123.3\left(\mathrm{C}^{3 \prime}\right.$ pypzH $), 127.0\left(\mathrm{C}^{5 \prime}\right.$ pypzH), 132.9 ( $\left.\mathrm{C}^{5,3} \mathrm{pzH}\right), 135.4\left(\mathrm{C}^{4}\right.$ pypzH $), 141.3\left(\mathrm{C}^{4 \prime}\right.$ pypzH), $141.9\left(\mathrm{C}^{3,5} \mathrm{pzH}\right), 151.2\left(\mathrm{C}^{2 \prime}\right.$ pypzH $), 153.9\left(\mathrm{C}^{3}\right.$ pypzH $), 154.2\left(\mathrm{C}^{6 \prime}\right.$ pypzH), $\mathrm{CO}$ not detected; all signals are singlets. IR (THF, $\mathrm{cm}^{-1}$ ): 2035 vs, 1935 s, 1920 vs IR (solid, cm ${ }^{-1}$ ): 3146 w, 2031 vs, 1918 vs, $1616 \mathrm{w}, 1440 \mathrm{w}, 1367 \mathrm{w}, 1284 \mathrm{~m}, 1240 \mathrm{~s}, 1222 \mathrm{~s}, 1159 \mathrm{~s}, 1138 \mathrm{~m}$, 1094 m, 1067 s, 1051 s, 1026 s, 910 w, 885 w, 802 w, 764 m, 634 m. Anal. Calcd for $\mathrm{C}_{15} \mathrm{H}_{11} \mathrm{~F}_{3} \mathrm{~N}_{5} \mathrm{O}_{6} \mathrm{ReS}$ : C, 28.48; H, 1.75; N, 11.07 . Found: C, 28.67; H, 1.84; N, 11.14.

fac-[Re(CO) $(\mathrm{dmpzH})(\mathrm{pypzH})] \mathrm{OTf}, 3 \mathrm{~b}$. The oil containing 2 $(0.5 \mathrm{mmol})$ obtained as indicated for $3 \mathbf{a}$ was dissolved in THF (25 $\mathrm{mL})$, and dmpzH was added $(0.048 \mathrm{~g}, 0.5 \mathrm{mmol})$. The solution was stirred at $40{ }^{\circ} \mathrm{C}$ for $24 \mathrm{~h}$. Work up as for $3 \mathbf{a}$ gave $\mathbf{3 b}$ as a pale brown microcrystalline solid. Yield $0.230 \mathrm{~g}(73 \%) .{ }^{1} \mathrm{H}$ NMR $(400 \mathrm{MHz}) \delta$ : 2.07 (s, $\mathrm{CH}_{3}$ dmpzH, 3H), 2.09 (s, $\left.\mathrm{CH}_{3} \mathrm{dmpzH}, 3 \mathrm{H}\right), 5.93\left(\mathrm{~s}, \mathrm{H}^{4}\right.$ dmpzH, $1 \mathrm{H}), 7.36\left(\mathrm{~d}, J=1.9 \mathrm{~Hz}, H^{5}\right.$ pypzH, $\left.1 \mathrm{H}\right), 7.79\left(\mathrm{~m}, H^{5 \prime}\right.$ pypzH, $1 \mathrm{H}), 8.33\left(\mathrm{~m}, H^{3 \prime}, H^{4 \prime}\right.$, and $H^{4}$ pypzH, $\left.3 \mathrm{H}\right), 9.39(\mathrm{~d}, J=4.3$ $\mathrm{Hz}, H^{6 \prime}$ pypzH, $\left.1 \mathrm{H}\right), 11.58$ (br s, $\mathrm{NH}$ dmpzH, $1 \mathrm{H}$ ), 14.17 (br s, $\mathrm{NH}$ pypzH, $1 \mathrm{H}) .{ }^{13} \mathrm{C}\left\{{ }^{1} \mathrm{H}\right\}$ NMR $(101 \mathrm{MHz}) \delta: 9.5\left(\mathrm{C}^{5,3} \mathrm{H}_{3} \mathrm{dmpzH}\right), 13.9$ $\left(\mathrm{C}^{3,5} \mathrm{H}_{3} \mathrm{dmpzH}\right), 106.7\left(\mathrm{C}^{5} \mathrm{pypzH}\right), 107.8\left(\mathrm{C}^{4} \mathrm{dmpzH}\right), 124.2\left(\mathrm{C}^{3 \prime}\right.$ pypzH $), 127.6\left(C^{5 \prime}\right.$ pypzH $), 136.1\left(C^{4}\right.$ pypzH $), 142.3\left(C^{4 \prime}\right.$ pypzH $)$, $145.1\left(C^{5,3} \mathrm{dmpzH}\right), 152.4\left(C^{2 \prime}\right.$ pypzH $), 154.5\left(C^{3,5} \mathrm{dmpzH}\right), 155.0$ $\left(\mathrm{C}^{3}\right.$ pypzH $), 155.8\left(\mathrm{C}^{61}\right.$ pypzH $), \mathrm{CO}$ not detected; all signals are singlets. IR (THF, $\mathrm{cm}^{-1}$ ): 2035 vs, $1937 \mathrm{~s}, 1918$ vs IR (solid, $\mathrm{cm}^{-1}$ ): 3371 w, 3155 w, 3038 w, 2963 w, 2931 w, 2029 vs, 1910 vs br, 1617 w, 1578 w, 1439 w, 1372 w, 1294 m, 1280 m, 1238 m, 1222 m, 1210 m, 1165 m, 1152 m, 1118 w, 1027 s, 817 w, 772 m, 632 s. Anal. Calcd for $\mathrm{C}_{17} \mathrm{H}_{15} \mathrm{~F}_{3} \mathrm{~N}_{5} \mathrm{O}_{6} \mathrm{ReS}$ : C, 30.91; H, 2.29; N, 10.60. Found: C, 31.07; $\mathrm{H}, 2.12 ; \mathrm{N}, 10.30$.

fac- $\left[\operatorname{Re}(\mathrm{CO})_{3}(\mathrm{indzH})(\mathrm{pypzH})\right] \mathrm{OTf}, 3 \mathrm{c}$. The oil containing $2(0.5$ $\mathrm{mmol}$ ) obtained as indicated for $3 \mathrm{a}$ was dissolved in THF $(25 \mathrm{~mL})$, and indzH was added $(0.059 \mathrm{~g}, 0.5 \mathrm{mmol})$. The solution was stirred at $40{ }^{\circ} \mathrm{C}$ for $24 \mathrm{~h}$. Work up as for $3 \mathrm{a}$ gave $3 \mathrm{c}$ as a yellow microcrystalline solid. Yield $0.326 \mathrm{~g}(95 \%) .{ }^{1} \mathrm{H}$ NMR $(500 \mathrm{MHz}) \delta: 7.19$ (dd, $J=8.1$ and $6.6 \mathrm{~Hz}, H^{6}$ indzH, $\left.1 \mathrm{H}\right), 7.42\left(\mathrm{~d}, J=1.9 \mathrm{~Hz}, H^{5}\right.$ pypzH, $\left.1 \mathrm{H}\right), 7.50$ (m, $H^{5}$ and $H^{4}$ indzH, $\left.2 \mathrm{H}\right), 7.66\left(\mathrm{~d}, J=8.1 \mathrm{~Hz}, H^{7}\right.$ indzH, $\left.1 \mathrm{H}\right), 7.79$ $\left(\mathrm{t}, J=5.6 \mathrm{~Hz}, H^{5 \prime}\right.$ pypzH, $\left.1 \mathrm{H}\right), 7.89\left(\mathrm{~s}, H^{3}\right.$ indzH, $\left.1 \mathrm{H}\right), 8.37\left(\mathrm{~m}, H^{4}\right.$, $H^{3 \prime}$, and $H^{4 \prime}$ pypzH, $\left.3 \mathrm{H}\right), 9.32\left(\mathrm{~d}, J=5.6 \mathrm{~Hz}, H^{6 \prime}\right.$ pypzH, $\left.1 \mathrm{H}\right), 12.93$ (sa, $\mathrm{NH}$ indzH, $1 \mathrm{H}), 14.20$ (sa, NH pypzH, $1 \mathrm{H}) .{ }^{13} \mathrm{C}\left\{{ }^{1} \mathrm{H}\right\}$ NMR (101 $\mathrm{MHz}) \delta: 105.9\left(C^{5}\right.$ pypzH), $110.2\left(C^{4}\right.$ indzH $), 120.9\left(C^{7}\right.$ indzH), $122.3\left(C^{7 \mathrm{a}}\right.$ indzH $), 122.7\left(C^{6}\right.$ indzH $), 123.4\left(C^{3 \prime}\right.$ pypzH $), 127.1\left(C^{5 \prime}\right.$ pypzH), $129.6\left(C^{5}\right.$ indzH $), 135.6\left(C^{4}\right.$ pypzH $), 137.6\left(C^{3}\right.$ indzH $)$, $141.3\left(C^{3 a}\right.$ indzH $), 141.4\left(C^{4 \prime}\right.$ pypzH $), 151.3\left(C^{2 \prime}\right.$ pypzH $), 154.0\left(C^{3}\right.$ pypzH), $154.3\left(C^{6 \prime}\right.$ pypzH), $C O$ not detected; all signals are singlets. IR (THF, $\mathrm{cm}^{-1}$ ): $2037 \mathrm{vs,} 1938 \mathrm{~s}, 1922$ vs IR (solid, $\mathrm{cm}^{-1}$ ): $3167 \mathrm{w}$, 2031 vs, 1933 vs br, 1630 w, 1618 w, 1439 w, 1285 m, 1241 m, 1224 m, 1154 m, 1125 m, 1092 w, 1050 s, 1027 s, 1003 s, 867 w, 773 m, $745 \mathrm{~m}, 700 \mathrm{w}, 630 \mathrm{~m}$. Anal. Calcd for $\mathrm{C}_{19} \mathrm{H}_{13} \mathrm{~F}_{3} \mathrm{~N}_{5} \mathrm{O}_{6} \mathrm{ReS}$ : C, 33.43; H, 1.92; N, 10.26. Found: C, 33.60; H, 2.06; N, 10.11 .

fac- $\left[\operatorname{Re}(\mathrm{CO})_{3}\left(\right.\right.$ pypzH- $\left.\kappa^{1} N\right)\left(\right.$ pypzH- $\left.\left.\kappa^{2} N, N\right)\right] O T f, 3 d$. The oil containing $2(0.5 \mathrm{mmol})$ obtained as indicated for $3 \mathbf{a}$ was dissolved in THF $(25 \mathrm{~mL})$, and pypzH was added $(0.073 \mathrm{~g}, 0.5 \mathrm{mmol})$. The solution was stirred at $40{ }^{\circ} \mathrm{C}$ for $24 \mathrm{~h}$. The volatiles were removed in vacuo, and the resulting yellow oil was crystallized in $\mathrm{CH}_{2} \mathrm{Cl}_{2} / \mathrm{Et}_{2} \mathrm{O}$ at $-20{ }^{\circ} \mathrm{C}$ giving a pale yellow microcrystalline solid, which was decanted, washed with $\mathrm{Et}_{2} \mathrm{O}(3 \times 3 \mathrm{~mL})$, and dried, yielding $0.285 \mathrm{~g}$ (80\%). ${ }^{1} \mathrm{H}$ NMR (400 MHz) $\delta: 6.90\left(\mathrm{~s}, H^{5}\right.$ pypzH-N, $\left.1 \mathrm{H}\right), 7.28(\mathrm{~s}$, $H^{4}$ pypzH-N, $\left.1 \mathrm{H}\right), 7.42\left(\mathrm{~m}, H^{5 \prime}\right.$ pypzH- $\left.N, 1 \mathrm{H}\right), 7.44(\mathrm{~d}, J=2.6 \mathrm{~Hz}$, $H^{5}$ pypzH-N,N, $\left.1 \mathrm{H}\right), 7.82\left(\mathrm{~d}, J=5.8 \mathrm{~Hz}, H^{5 \prime}\right.$ pypzH-N,N, $\left.1 \mathrm{H}\right), 7.85$ $\left(\mathrm{d}, J=7.6 \mathrm{~Hz}, H^{3 \prime}\right.$ pypzH-N, $\left.1 \mathrm{H}\right), 7.89\left(\mathrm{~d}, J=7.6 \mathrm{~Hz}, H^{4 \prime}\right.$ pypzH-N, $1 \mathrm{H}), 8.37\left(\mathrm{~d}, J=2.6 \mathrm{~Hz}, H^{4}\right.$ pypzH-N,N, $\left.1 \mathrm{H}\right), 8.38\left(\mathrm{~m}, H^{4 \prime}\right.$ pypzH$N, N, 1 \mathrm{H}), 8.41\left(\mathrm{~s}, H^{3 \prime}\right.$ pypzH- $\left.N, N, 1 \mathrm{H}\right), 8.59\left(\mathrm{~d}, J=3.7 \mathrm{~Hz}, H^{6 \prime}\right.$ pypzH-N, $1 \mathrm{H}), 9.32\left(\mathrm{~d}, J=5.8 \mathrm{~Hz}, H^{6 \prime}\right.$ pypzH-N,N, $\left.1 \mathrm{H}\right), 12.94$ (br s, $\mathrm{NH}, 1 \mathrm{H}), 14.06\left(\right.$ br s, NH, 1H). ${ }^{13} \mathrm{C}\left\{{ }^{1} \mathrm{H}\right\}$ NMR $(101 \mathrm{MHz}) \delta: 105.5$ $\left(C^{5}\right.$ pypzH- $\left.N\right), 105.8\left(C^{5}\right.$ pypzH-N,N), $121.2\left(C^{3 \prime}\right.$ pypzH-N $), 123.4$ ( $C^{3 \prime}$ pypzH-N,N), 124.4 ( $C^{5 \prime}$ pypzH-N), 126.9 ( $C^{5 \prime}$ pypzH-N,N), 135.4 ( $C^{4}$ pypzH-N,N), 137.5 ( $C^{4 \prime}$ pypzH-N), 141.3 ( $C^{4 \prime}$ pypzH-
$N, N), 143.2\left(C^{4}\right.$ pypzH-N $), 145.9\left(C^{2,3}\right.$ pypzH-N $), 145.9\left(C^{3,2 \prime}\right.$ pypzH-N), 149.7 ( $C^{6 \prime}$ pypzH-N), $151.3\left(C^{2 \prime}\right.$ pypzH-N,N), $154.0\left(C^{3}\right.$ pypzH-N,N), $154.4\left(C^{6 /}\right.$ pypzH-N,N), $C \mathrm{O}$ not detected; all signals are singlets. IR (THF, cm ${ }^{-1}$ ): 2036 vs, $1934 \mathrm{~s}, 1921$ vs IR (solid, $\mathrm{cm}^{-1}$ ): 3157 w, 2033 vs, 1912 vs br, 1615 w, 1456 w, 1432 w, 1274 m, 1242 s, 1223 s, 1154 m, 1104 w, 1093 w, 1056 w, 1027 w, 994 s, 970 s, 805 s, 775 s, 709 w, 632 s. Anal. Calcd for $\mathrm{C}_{20} \mathrm{H}_{14} \mathrm{~F}_{3} \mathrm{~N}_{6} \mathrm{O}_{6} \mathrm{ReS}$ : C, 33.85; H, 1.99; N, 11.84. Found: C, 33.98; H, 1.88; N, 11.74.

fac- $\left[\operatorname{Re}(\mathrm{CO})_{3}(\mathrm{pzH})(\mathrm{pypz})\right], 4 \mathrm{a} . \mathrm{Na}_{2} \mathrm{CO}_{3}(0.064 \mathrm{~g}, 0.6 \mathrm{mmol})$ was added to a solution of $3 \mathrm{a}(0.127 \mathrm{~g}, 0.2 \mathrm{mmol})$ in THF $(10 \mathrm{~mL})$. The mixture was stirred at r.t. for $1 \mathrm{~h}$. The reaction mixture was filtered, and hexane (ca. $20 \mathrm{~mL}$ ) was added to the filtrate. The solution was concentrated and cooled to $-20{ }^{\circ} \mathrm{C}$, giving a pale yellow microcrystalline solid which was decanted, washed with hexane (3 $\times 3 \mathrm{~mL}$ approximately), and dried in vacuo, yielding $0.060 \mathrm{~g}(62 \%)$. ${ }^{1} \mathrm{H}$ NMR $(500 \mathrm{MHz}) \delta: 6.27\left(\mathrm{t}, J=2.4 \mathrm{~Hz}, H^{4} \mathrm{pzH}, 1 \mathrm{H}\right), 6.81(\mathrm{~d}, J=$ $1.9 \mathrm{~Hz}, H^{5}$ pypz, $\left.1 \mathrm{H}\right), 7.29$ (d, $\left.J=2.2 \mathrm{~Hz}, H^{3,5} \mathrm{pzH}, 1 \mathrm{H}\right), 7.44$ (ddd $J$ $=7.3,5.6$, and $1.4 \mathrm{~Hz}, H^{5 \prime}$ pypz, $\left.1 \mathrm{H}\right), 7.58\left(\mathrm{~d}, J=2.0 \mathrm{~Hz}, H^{4}\right.$ pypz, $1 \mathrm{H}), 7.80\left(\mathrm{~d}, J=2.6 \mathrm{~Hz}, H^{5,3} \mathrm{pzH}, 1 \mathrm{H}\right), 7.91\left(\mathrm{~d}, J=8.0 \mathrm{~Hz}, H^{3 \prime}\right.$ pypz, $1 \mathrm{H}), 8.09\left(\mathrm{td}, J=7.8\right.$ and $1.5 \mathrm{~Hz}, H^{4 \prime}$ pypz, $\left.1 \mathrm{H}\right), 9.09(\mathrm{dt}, J=5.6$ and $1.3 \mathrm{~Hz}, H^{6 \prime}$ pypz, $\left.1 \mathrm{H}\right), \mathrm{NH}$ not detected. ${ }^{13} \mathrm{C}\left\{{ }^{1} \mathrm{H}\right\} \mathrm{NMR}(101 \mathrm{MHz})$ $\delta$ : 104.4 ( $C^{5}$ pypz $), 107.3\left(C^{4} \mathrm{pzH}\right), 120.9$ ( $C^{3 \prime}$ pypz $), 123.5\left(C^{5 \prime}\right.$ pypz), $132.6\left(C^{5,3} \mathrm{pzH}\right), 140.8\left(C^{4 \prime}\right.$ pypz $), 142.5\left(C^{3,5} \mathrm{pzH}\right), 143.0$ ( $C^{4}$ pypz $), 153.4$ ( $C^{6 \prime}$ pypz $), 151.2$ ( $C^{3}$ pypz $), 155.4$ ( $C^{2 \prime}$ pypz $), C O$ not detected; all signals are singlets. IR (THF, $\left.\mathrm{cm}^{-1}\right): 2021 \mathrm{~s}, 1914 \mathrm{~s}$, 1900 s. IR (solid, $\mathrm{cm}^{-1}$ ): $3676 \mathrm{w}, 3571 \mathrm{w}, 2961 \mathrm{w}, 2914 \mathrm{w}, 2018 \mathrm{~s}$, $1885 \mathrm{~s} \mathrm{br}, 1609 \mathrm{~m}, 1536 \mathrm{~m}, 1482 \mathrm{w}, 1456 \mathrm{w}, 1430 \mathrm{w}, 1371 \mathrm{w}, 1350 \mathrm{w}$, 1257 s, 1232 s, 1171 s, 1035 s, 978 w, 942 w, 901 w, 879 w, 843 w, $801 \mathrm{w}, 778 \mathrm{~m}, 765 \mathrm{~m}, 750 \mathrm{w}, 709$ w, $631 \mathrm{~s}, 588$ w, 537 w, $516 \mathrm{~m}, 490$ w, 477 w, 422 m. Anal. Calcd for $\mathrm{C}_{14} \mathrm{H}_{10} \mathrm{~N}_{5} \mathrm{O}_{3}$ Re: C, 34.85; H, 2.09; $\mathrm{N}, 14.52$. Found: $\mathrm{C}, 34.68 ; \mathrm{H}, 2.14 ; \mathrm{N}, 14.33$.

fac-[Re(CO) $\left.)_{3}(\mathrm{dmpzH})(\mathrm{pypz})\right], 4 \mathrm{~b}$. The same procedure as that for $4 \mathrm{a}$, using $3 \mathbf{b}(0.132 \mathrm{~g}, 0.2 \mathrm{mmol})$ as starting material, gave $0.061 \mathrm{~g}$ $(60 \%)$ of $\mathbf{4 b}$ as a white-yellow microcrystalline solid. ${ }^{1} \mathrm{H}$ NMR (400 $\mathrm{MHz}) \delta: 2.05$ (s, $\left.\mathrm{CH}_{3} \mathrm{dmpzH}, 3 \mathrm{H}\right), 2.19$ (s, $\left.\mathrm{CH}_{3} \mathrm{dmpzH}, 3 \mathrm{H}\right), 5.82$ (s, $H^{4}$ dmpzH, $\left.1 \mathrm{H}\right), 6.74\left(\mathrm{~d}, J=2.1 \mathrm{~Hz}, H^{5}\right.$ pypz, $\left.1 \mathrm{H}\right), 7.37(\mathrm{dd}, J=$ 7.5 and $5.8 \mathrm{~Hz}, H^{5 \prime}$ pypz, $\left.1 \mathrm{H}\right), 7.64\left(\mathrm{~d}, J=2.1 \mathrm{~Hz}, H^{4}\right.$ pypz, $\left.1 \mathrm{H}\right), 7.82$ $\left(\mathrm{d}, J=7.5 \mathrm{~Hz}, H^{3 \prime}\right.$ pypz, $\left.1 \mathrm{H}\right), 8.02\left(\mathrm{t}, J=7.5 \mathrm{~Hz}, H^{4 \prime}\right.$ pypz, $\left.1 \mathrm{H}\right), 9.08$ $\left(\mathrm{d}, J=5.8 \mathrm{~Hz}, H^{6 \prime}\right.$ pypz, $\left.1 \mathrm{H}\right), 10.38$ (br s, $\left.\mathrm{NH} \mathrm{dmpzH}, 1 \mathrm{H}\right) .{ }^{13} \mathrm{C}\left\{{ }^{1} \mathrm{H}\right\}$ NMR (101 MHz) $\delta: 9.7\left(\mathrm{CH}_{3} \mathrm{dmpzH}\right), 13.7\left(\mathrm{CH}_{3} \mathrm{dmpzH}\right), 104.1$ ( $C^{5}$ pypz), $106.2\left(C^{4} \mathrm{dmpzH}\right), 120.3\left(C^{31}\right.$ pypz $), 122.6$ ( $C^{51}$ pypz), 139.9 ( $C^{41}$ pypz $), 142.0\left(C^{5,3} \mathrm{dmpzH}\right), 143.0\left(C^{4}\right.$ pypz $), 152.2\left(C^{3}\right.$ pypz), 152.3 ( $\left.C^{3,5} \mathrm{dmpzH}\right), 153.0$ ( $\left.C^{6 \prime} \mathrm{pypz}\right), 155.6$ ( $\left.C^{2 \prime} \mathrm{pypz}\right), 194.1$ (CO), 195.9 (CO), 198.0 (CO); all signals are singlets. IR (THF, $\mathrm{cm}^{-1}$ ): $2021 \mathrm{~s}, 1916 \mathrm{~s}, 1897 \mathrm{~s}$. IR (solid, $\mathrm{cm}^{-1}$ ): $3899 \mathrm{w}, 3272 \mathrm{~m}$, 2961 w, 2853 w, 2012 s, 1886 vs br, 1610 m, 1573 m, 1539 m, 1454 m, 1419 m, 1376 m, 1346 m, 1259 m, 1201 m, 1156 m, 1146 m, 1127 m, 1096 m, 1049 m, 1017 m, 972 m, 929 m, 799 m, 754 s, 698 m, 629 $\mathrm{m}, 614 \mathrm{~m}, 546 \mathrm{~m}, 538 \mathrm{~m}, 491 \mathrm{~m}, 476 \mathrm{~m}$. Anal. Calcd for $\mathrm{C}_{16} \mathrm{H}_{14} \mathrm{~N}_{5} \mathrm{O}_{3}$ Re: $\mathrm{C}, 37.64 ; \mathrm{H}, 2.76 ; \mathrm{N}, 13.72$. Found: $\mathrm{C}, 37.51 ; \mathrm{H}$, 2.95; N, 13.94 .

fac- $\left[\operatorname{Re}(\mathrm{CO})_{3}(\right.$ indzH $\left.)(\mathrm{pypz})\right], 4 \mathrm{c}$. The same procedure as that for $4 \mathrm{a}$, using $3 \mathrm{c}(0.132 \mathrm{~g}, 0.2 \mathrm{mmol})$ as starting material, gave $0.063 \mathrm{~g}$ $(59 \%)$ of $4 \mathrm{c}$ as a white-yellow microcrystalline solid. ${ }^{1} \mathrm{H}$ NMR (400 $\mathrm{MHz}) \delta: 6.74\left(\mathrm{~s}, H^{5}\right.$ pypz, $\left.1 \mathrm{H}\right), 7.13\left(\mathrm{~m}, H^{5}\right.$ indzH, $\left.1 \mathrm{H}\right), 7.31(\mathrm{t}, J=$ $6.0 \mathrm{~Hz}, H^{5 \prime}$ pypz, $\left.1 \mathrm{H}\right), 7.41\left(\mathrm{~m}, H^{6}\right.$ indzH, $\left.1 \mathrm{H}\right), 7.55(\mathrm{~d}, J=8.9 \mathrm{~Hz}$, $H^{7}$ indzH, $\left.1 \mathrm{H}\right), 7.59\left(\mathrm{~s}, H^{4}\right.$ pypz, $\left.1 \mathrm{H}\right), 7.65\left(\mathrm{~d}, J=11.1 \mathrm{~Hz}, H^{4}\right.$ indzH, $1 \mathrm{H}), 7.68\left(\mathrm{~s}, H^{3}\right.$ indzH, $\left.1 \mathrm{H}\right), 7.78\left(\mathrm{~d}, J=8.3 \mathrm{~Hz}, H^{3 \prime}\right.$ pypz, $\left.1 \mathrm{H}\right), 7.98$ (dd, $J=8.3$ and $6.0 \mathrm{~Hz}, H^{4 \prime}$ pypz, $\left.1 \mathrm{H}\right), 9.02\left(\mathrm{~d}, J=6.0 \mathrm{~Hz}, H^{6 \prime}\right.$ pypz, $1 \mathrm{H}), \mathrm{NH}$ not detected. ${ }^{13} \mathrm{C}\left\{{ }^{1} \mathrm{H}\right\}$ NMR $(101 \mathrm{MHz}) \delta: 103.7\left(\mathrm{C}^{5}\right.$ pypz), 110.2 ( $C^{7}$ indzH), 120.0 ( $C^{3 \prime}$ pypz), 120.2 ( $C^{5}$ indz), 120.8 ( $C^{4}$ indzH $), 122.2\left(C^{3 \mathrm{a}}\right.$ indzH $), 122.6\left(C^{5 \prime}\right.$ pypz $), 128.9\left(C^{6}\right.$ inzH $)$, $137.2\left(C^{3}\right.$ indzH $), 139.9\left(C^{4}\right.$ pypz $), 140.8\left(C^{7 a}\right.$ indzH $), 142.4\left(C^{4}\right.$ pypz), 152.6 ( $C^{6 \prime}$ pypz $), 155.3$ ( $C^{3}$ pypz $), 155.6\left(C^{2 \prime}\right.$ pypz $), C O$ not detected; all signals are singlets. IR (THF, $\left.\mathrm{cm}^{-1}\right): 2022 \mathrm{~s}, 1918 \mathrm{~s}$, 1900 s. IR (solid, cm ${ }^{-1}$ ): 3675 w, 3155 w, 2962 m, 2017 s, 1895 s br, $1611 \mathrm{~m}, 1538 \mathrm{w}, 1503 \mathrm{w}, 1457 \mathrm{w}, 1431 \mathrm{w}, 1388 \mathrm{w}, 1355 \mathrm{w}, 1257 \mathrm{~s}$, $1232 \mathrm{~m}, 1172$ s, 1079 s, 1033 s, 952 w, 869 w, 845 w, 795 s, 762 m, $741 \mathrm{~m}, 707 \mathrm{w}, 631 \mathrm{~m}, 587 \mathrm{w}, 534 \mathrm{~m}, 515$ w, 476 w, $428 \mathrm{~m}$. Anal. 
Calcd for $\mathrm{C}_{18} \mathrm{H}_{12} \mathrm{~N}_{5} \mathrm{O}_{3}$ Re: C, 40.60; H, 2.27; N, 13.15. Found: C, 40.44; H, 2.08; N, 13.04 .

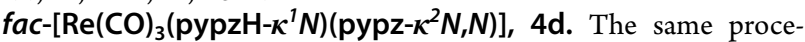
dure as that for $4 \mathrm{a}$, using $3 \mathrm{~d}(0.132 \mathrm{~g}, 0.2 \mathrm{mmol})$ as starting material, gave $0.055 \mathrm{~g}(49 \%)$ of $4 \mathrm{~d}$ as a pale yellow microcrystalline solid. ${ }^{1} \mathrm{H}$ NMR $(400 \mathrm{MHz}) \delta: 6.53\left(\mathrm{~s}, H^{5}\right.$ pypz-N,N, $\left.1 \mathrm{H}\right), 6.67\left(\mathrm{~s}, H^{5}\right.$ pypzH$N, 1 \mathrm{H}), 7.16\left(\mathrm{~s}, H^{5 \prime}\right.$ pypzH-N, $\left.1 \mathrm{H}\right), 7.30\left(\mathrm{~m}, H^{4}\right.$ pypz- $\left.N, N, 1 \mathrm{H}\right), 7.33$ $\left(\mathrm{m}, H^{5 \prime}\right.$ pypz-N,N, $\left.1 \mathrm{H}\right), 7.51\left(\mathrm{~m}, H^{4}\right.$ pypzH-N, $\left.1 \mathrm{H}\right), 7.55\left(\mathrm{~m}, H^{3 \prime}\right.$ pypzH-N, $1 \mathrm{H}), 7.71\left(\mathrm{~m}, H^{4 \prime}\right.$ pypzH- $\left.N, 1 \mathrm{H}\right), 7.73\left(\mathrm{~m}, H^{3 \prime}\right.$ pypz- $N, N$, $1 \mathrm{H}), 7.94\left(\mathrm{t}, J=7.8 \mathrm{~Hz}, H^{4 \prime}\right.$ pypz- $\left.N, N, 1 \mathrm{H}\right), 8.41\left(\mathrm{~s}, H^{6 \prime}\right.$ pypzH- $N$, $1 \mathrm{H}), 9.04\left(\mathrm{~d}, J=5.6 \mathrm{~Hz}, H^{6 \prime}\right.$ pypz- $\left.N, N, 1 \mathrm{H}\right), \mathrm{NH}$ not detected. ${ }^{13} \mathrm{C}\left\{{ }^{1} \mathrm{H}\right\}$ NMR $(101 \mathrm{MHz}) \delta: 102.1\left(C^{5}\right.$ pypz-N,N), $102.8\left(C^{5}\right.$ pypzH-N), $103.2\left(C^{4}\right.$ pypz-N,N), $119.5\left(C^{3 \prime}\right.$ pypzH-N $), 119.8\left(C^{3 \prime}\right.$ pypz- $N, N), 120.9\left(C^{2 \prime}\right.$ pypzH-N), $122.3\left(C^{5 \prime}\right.$ pypz- $\left.N, N\right), 136.9\left(C^{4 \prime}\right.$ pypzH-N $), 139.1\left(C^{4}\right.$ pypz-N,N), $140.3\left(C^{3}\right.$ pypz- $\left.N, N\right), 141.7\left(C^{4}\right.$ pypzH-N), $148.9\left(C^{5 \prime}\right.$ pypzH-N), $149.2\left(C^{6 \prime}\right.$ pypzH-N), $151.4\left(C^{3}\right.$ pypzH-N), $151.9\left(C^{6 \prime}\right.$ pypz-N,N), $155.9\left(C^{2 \prime}\right.$ pypz-N,N), CO not detected; all signals are singlets. IR (THF, $\left.\mathrm{cm}^{-1}\right)$ : $2021 \mathrm{~s}, 1918 \mathrm{~s}$, 1896 s. IR (solid, cm ${ }^{-1}$ ): 2973 w, 2932 w, 2006 vs, 1880 vs, 1868 vs, $1696 \mathrm{~m}, 1612 \mathrm{~m}, 1592 \mathrm{~m}, 1565 \mathrm{~m}, 1536 \mathrm{~m}, 1512 \mathrm{~m}, 1454 \mathrm{~m}, 1427 \mathrm{~m}$, 1347 m, 1149 m, 1128 m, 1118 m, 1089 m, 1056 m, 972 w, 946 w, $761 \mathrm{~s}, 708 \mathrm{~m}, 643 \mathrm{~m}, 627 \mathrm{~m}$. Anal. Calcd for $\mathrm{C}_{19} \mathrm{H}_{13} \mathrm{~N}_{6} \mathrm{O}_{3}$ Re: $\mathrm{C}$, 40.78; H, 2.34; N, 15.02. Found: C, 40.52; H, 2.19; N, 14.72 .

$\mathrm{Na}\left[\mathrm{fac}-\left\{\operatorname{Re}(\mathrm{CO})_{3}(\mathrm{pz})(\mathrm{pypz})\right\}\right]$, 5a. Method A: 3a (0.006 g, 0.01 $\mathrm{mmol})$ was dissolved in $\left(\mathrm{CD}_{3}\right)_{2} \mathrm{CO}$ or THF $(0.5 \mathrm{~mL})$, and $0.025 \mathrm{~mL}$ of $1 \mathrm{M} \mathrm{NaOH}$ solution $(0.025 \mathrm{mmol})$ in $\mathrm{D}_{2} \mathrm{O}$ or $\mathrm{H}_{2} \mathrm{O}$ was added. Method B: 4a $(0.005 \mathrm{~g}, 0.01 \mathrm{mmol})$ and $0.012 \mathrm{~mL}$ of $1 \mathrm{M} \mathrm{NaOH}$ solution $(0.012 \mathrm{mmol})$ was added. The compound was not isolated. ${ }^{1} \mathrm{H}$ NMR $(500 \mathrm{MHz}) \delta: 8.84\left(\mathrm{~m}, H^{4} \mathrm{pzH}, 1 \mathrm{H}\right), 6.65(\mathrm{~d}, J=1.9 \mathrm{~Hz}$, $H^{5}$ pypz, $\left.1 \mathrm{H}\right), 6.91\left(\mathrm{~d}, J=2.0 \mathrm{~Hz}, H^{3,5} \mathrm{pzH}, 1 \mathrm{H}\right), 7.28\left(\mathrm{~m}, H^{5 \prime}\right.$ and $H^{4}$ pypz, $2 \mathrm{H}), 7.48\left(\mathrm{~d}, J=1.9 \mathrm{~Hz}, H^{5,3} \mathrm{pzH}, 1 \mathrm{H}\right), 7.72(\mathrm{dt}, J=8.0$ and 1.2 $\mathrm{Hz}, H^{3 \prime}$ pypz, $\left.1 \mathrm{H}\right), 7.93\left(\mathrm{td}, J=7.7\right.$ and $1.6 \mathrm{~Hz}, H^{4 \prime}$ pypz, $\left.1 \mathrm{H}\right), 9.01$ $\left(\mathrm{dt}, J=5.6\right.$ and $1.3 \mathrm{~Hz}, H^{6 \prime}$ pypz, $\left.1 \mathrm{H}\right)$. IR $\left(\mathrm{THF}, \mathrm{cm}^{-1}\right): 2007 \mathrm{~s}, 1896$ s, $1880 \mathrm{~s}$.

$\mathrm{Na}\left[\right.$ fac- $\left.\left\{\operatorname{Re}(\mathrm{CO})_{3}(\mathrm{dmpz})(\mathrm{pypz})\right\}\right]$, 5b. Method A: 3b (0.007 g, $0.01 \mathrm{mmol})$ was dissolved in $\left(\mathrm{CD}_{3}\right)_{2} \mathrm{CO}$ or THF $(0.5 \mathrm{~mL})$, and 0.025 $\mathrm{mL}$ of $1 \mathrm{M} \mathrm{NaOH}$ solution $(0.025 \mathrm{mmol})$ in $\mathrm{D}_{2} \mathrm{O}$ or $\mathrm{H}_{2} \mathrm{O}$ was added. Method B: $4 \mathbf{b}(0.005 \mathrm{~g}, 0.01 \mathrm{mmol})$ and $0.012 \mathrm{~mL}$ of $1 \mathrm{M} \mathrm{NaOH}$ solution $(0.012 \mathrm{mmol})$ was added. The compound was not isolated. ${ }^{1} \mathrm{H}$ NMR $(400 \mathrm{MHz}) \delta: 1.85\left(\mathrm{~s}, \mathrm{CH}_{3}\right.$ dmpzH, 3H), $1.91\left(\mathrm{~s}, \mathrm{CH}_{3}\right.$ dmpzH, 3H), $5.20\left(\mathrm{~s}, H^{4} \mathrm{dmpzH}, 1 \mathrm{H}\right), 6.53\left(\mathrm{~s}, H^{5}\right.$ pypz, $\left.1 \mathrm{H}\right), 7.21(\mathrm{t}$, $J=4.5 \mathrm{~Hz}, H^{5 \prime}$ pypz, $\left.1 \mathrm{H}\right), 7.43\left(\mathrm{~s}, H^{4}\right.$ pypz, $\left.1 \mathrm{H}\right), 7.58(\mathrm{~d}, J=5.5 \mathrm{~Hz}$, $H^{3 \prime}$ pypz, $\left.1 \mathrm{H}\right), 7.82\left(\mathrm{t}, J=5.5 \mathrm{~Hz}, H^{4 \prime}\right.$ pypz, $\left.1 \mathrm{H}\right), 9.13(\mathrm{~d}, J=3.5 \mathrm{~Hz}$, $H^{6 /}$ pypz, 1H). IR (THF, $\mathrm{cm}^{-1}$ ): $2009 \mathrm{~s}, 1898 \mathrm{~s}, 1885 \mathrm{~s}$.

$\mathrm{Na}\left[\right.$ fac- $\left\{\operatorname{Re}(\mathrm{CO})_{3}\right.$ (indz)(pypz)\}], 5c. Method A: 3c (0.007 g, 0.01 $\mathrm{mmol})$ was dissolved in $\left(\mathrm{CD}_{3}\right)_{2} \mathrm{CO}$ or THF $(0.5 \mathrm{~mL})$, and $0.025 \mathrm{~mL}$ of $1 \mathrm{M} \mathrm{NaOH}$ solution $(0.025 \mathrm{mmol})$ in $\mathrm{D}_{2} \mathrm{O}$ or $\mathrm{H}_{2} \mathrm{O}$ was added. Method B: $4 \mathrm{c}(0.005 \mathrm{~g}, 0.01 \mathrm{mmol})$ and $0.012 \mathrm{~mL}$ of $1 \mathrm{M} \mathrm{NaOH}$ solution $(0.012 \mathrm{mmol})$ was added. The compound was not isolated. ${ }^{1} \mathrm{H}$ NMR $(500 \mathrm{MHz}) \delta: 6.73\left(\mathrm{~s}, H^{5} \mathrm{pypz}, 1 \mathrm{H}\right), 6.96\left(\mathrm{~m}, H^{5}\right.$ indzH, $1 \mathrm{H}), 7.22\left(\mathrm{~m}, H^{5 \prime}\right.$ pypz, $\left.1 \mathrm{H}\right), 7.38\left(\mathrm{~m}, H^{6}\right.$ indzH, $\left.1 \mathrm{H}\right), 7.46(\mathrm{~d}, J=10$ $\mathrm{Hz}, H^{7}$ indzH, $\left.1 \mathrm{H}\right), 7,56\left(\mathrm{~m}, H^{4}\right.$ pypz and $H^{4}$ indzH, $\left.2 \mathrm{H}\right), 7.65(\mathrm{~m}$, $H^{3}$ indzH, $\left.1 \mathrm{H}\right), 7.80\left(\mathrm{~d}, J=7 \mathrm{~Hz}, H^{3 \prime}\right.$ pypz, $\left.1 \mathrm{H}\right), 7.99\left(\mathrm{~m}, H^{4 \prime}\right.$ pypz, $1 \mathrm{H}), 9.15\left(\mathrm{~d}, J=4.0 \mathrm{~Hz}, H^{6 \prime}\right.$ pypz, 1H). IR (THF, $\left.\mathrm{cm}^{-1}\right): 2009 \mathrm{~s}$, $1898 \mathrm{~s}, 1884 \mathrm{~s}$.

Photophysical Studies. All solvents used for spectroscopic studies were of spectroscopic grade and used as received. Ultravioletvisible (UV-vis) and luminescence spectra were recorded in optically dilute solutions (from $1 \times 10^{-5}$ to $5 \times 10^{-5} \mathrm{M}$ ), at room temperature with a hermetic quartz cuvette $(1 \mathrm{~cm} \times 1 \mathrm{~cm})$, using a Hitachi U-3900 and an F-7000 Hitachi Fluorescence spectrophotometers, respectively. UV-vis spectra were recorded in non-deaerated solvents, while emission was recorded both in deaerated and non-deaerated solvents. Luminescence decay lifetimes were measured in rigorously deaerated solvents, using a time-correlated single photon counting instrument (FLS980 Series, Edinburgh instruments) with a $405 \mathrm{~nm}$ pulsed LED (Edinburgh instruments, EPL-510) light source having 50-500 ns pulse at r.t. The absolute luminescence quantum yields in each solvent were measured both in rigorously deaerated solvents and in the presence of air using the integrating sphere accessory with a FLS980 Series Edinburgh instrument at r.t., wherein the solvent was used as a reference.

Electrochemical Studies. Electrochemical measurements were carried out with Dropsens $\mu$ Stat 400 (range -4 to $+4 \mathrm{~V}$, software DropView 8400 Version 2.2) or Dropsens $\mu$ Stat 300 (range -2 to +2 $\mathrm{V}$ ) or PalmSens 3 potentiostats (range -5 to $+5 \mathrm{~V}$, software PSTrace 4 Version 4.4.2). Unless otherwise stated, $\mathrm{CVs}$ were scanned at 200 $\mathrm{mVs}-1$, in $\mathrm{MeCN}(5 \mathrm{~mL}), 0.1 \mathrm{M}^{n} \mathrm{Bu}_{4} \mathrm{PF}_{6}$ supporting electrolyte, purging with $\mathrm{Ar}$ or $\mathrm{CO}_{2}$ at room temperature through a PTFE tubing. Working electrodes were of glassy carbon ( $3 \mathrm{~mm}$ diameter). The auxiliary electrode was a platinum wire. The reference electrodes used were $\mathrm{Ag} / \mathrm{AgCl}(3 \mathrm{M} \mathrm{NaCl}) \mathrm{MF}-2052 \mathrm{BASi}$ (separated from the bulk solution by a "thirsty" Vycor frit) or a silver wire pseudoreference electrode. Ferrocene was added at the end of each experiment. The observed ferrocenium/ferrocene couple was $E_{1 / 2}=0.443 \pm 0.005 \mathrm{~V}$ vs $\mathrm{Ag} / \mathrm{AgCl}$. Potential values measured with the Ag wire have plenty of uncertainty, and at the end of the experiment, measures must be carried out with the $\mathrm{Ag} / \mathrm{AgCl}(3 \mathrm{M} \mathrm{NaCl})$ electrode. The solubility of saturated $\mathrm{CO}_{2}$ in $\mathrm{MeCN}$ has been reported to be $0.28 \mathrm{M}$ at $25^{\circ} \mathrm{C} .{ }^{35}$ Changing the atmosphere from pure Ar to pure $\mathrm{CO}_{2}$ or vice versa required bubbling with the new gas for not less than 5 min, lasting a such time that the CVs obtained were the same as those obtained in the first scan under a specific atmosphere. Bubbling was kept during the interim between scans. During scan time, the PTFE was lifted and kept above the surface of the solution to avoid agitation.

Controlled Potential Electrolysis (CPE). All the electrochemical experiments were carried out with a VSP or a PS-50 potentiostat from Bio-Logic, equipped with the EC-Lab software. For CV measurements, a double-walled jacketed single-compartment cell was used. It was filled with $\mathrm{Ar}$ or $\mathrm{CO}_{2}$-sparged $\mathrm{TBAPF}_{6} / \mathrm{CH}_{3} \mathrm{CN}(0.1 \mathrm{M})$ electrolyte solutions of the complex under study. Before starting $\mathrm{CPE}, \mathrm{CVs}$ of the blank and catalyst solutions were recorded in the presence of ferrocene $(\mathrm{Fc}, 1 \mathrm{mM})$ as an internal standard, using glassy carbon $(\mathrm{GC}$, diameter $=0.1 \mathrm{~cm})$ disks as the working electrode and an $\mathrm{Ag}$ wire as pseudoreference electrode, immerged in a bridge tube containing the same electrolyte solution $\left(0.1 \mathrm{M}, \mathrm{TBAPF}_{6} / \mathrm{CH}_{3} \mathrm{CN}\right)$ and separated from the working solution by a Teflon tip. In CPE, a glassy carbon rod (surface area $\approx 2.4 \mathrm{~cm}^{2}$ ) was used as the working electrode. In the anodic compartment, a Pt wire immerged in a 30 $\mathrm{mM}$ solution of sacrificial $\mathrm{Fc}$ was used as counter electrode (CE). The two compartments of the cell were separated by a porous ceramic frit. A constant gas flow $\left(30 \mathrm{~mL} \cdot \mathrm{min}^{-1}\right)$ was maintained through the electrolysis, and on-line analysis was accomplished by gas chromatography every ca. $5 \mathrm{~min}$. In all cases, the gas flow was controlled using a mass-flow controller (Alicat).

On-Line Gas Analysis. On-line analysis of the gas evolution during electrolysis was performed using an Agilent 490 micro gas chromatograph equipped with a thermal conductivity detector and a Molesieve $5 \AA$ A column was calibrated with different $\mathrm{H}_{2} / \mathrm{He} / \mathrm{CO} / \mathrm{CH}_{4}$ mixtures of known composition.

Computational Details. All calculations have been performed using the Gaussian 16 program package, ${ }^{36}$ in which the B3LYP functional was used..$^{37}$ Geometry optimizations were performed under no symmetry restrictions, using initial coordinates derived from X-ray data of the same complexes when availables, and frecuency analyses were performed to ensure that a minimum structure with no imaginary frecuencies was achieved in each case. On the basis of the optimized ground- and excited-state geometries, the absorption and emission properties were calculated by TD-DFT ${ }^{38}$ at the B3LYP level. In the calculations, effective core potentials (ECP) and their associated double- $\zeta$ LANL2DZ basis set were used for the rhenium atoms, ${ }^{39}$ while the light elements $(\mathrm{O}, \mathrm{N}, \mathrm{C}$, and $\mathrm{H})$ were described with the $6-31 \mathrm{G}(\mathrm{d}, \mathrm{p})$ basis. ${ }^{40}$ The contribution of every fragment in the molecules studied to the different orbitals involved in the optical transitions was calculated with the AOMix program, ${ }^{41}$ and the graphical representation of the orbitals was made with the help of GaussView. ${ }^{42}$ 


\section{ASSOCIATED CONTENT}

\section{(s) Supporting Information}

The Supporting Information is available free of charge at https://pubs.acs.org/doi/10.1021/acs.inorgchem.0c01654.

Chemical shifts of a $\mathrm{Me}_{2} \mathrm{CO}-d_{6}$ solution of $3 \mathbf{b}$ after successive additions of $\mathrm{NaOH}$ (aqueous), obtaining successively $\mathbf{4 b}$ and $\mathbf{5 b}$. Normalized $\mathrm{UV} /$ vis absorption (black) and emission (blue, $\lambda_{\mathrm{ex}}=360 \mathrm{~nm}$ ) spectra at 298 $\mathrm{K}$, in deaerated solvents in optically dilute solutions. Absorption and emission (\% emission intensity decrease $\left.=100 \times I_{\text {nondeaerated }} / I_{\text {aerated }}\right)$ data at $298 \mathrm{~K}$ in different solvents. Frontier molecular orbital compositions (\%) in the ground state for complexes $3 \mathbf{a}$ and $4 \mathbf{a}$ at the PBE1PBE Level. Experimental raw values observed using silver wire (as pseudoreference electrode) or $\mathrm{AgCl} / \mathrm{Ag}$ (3 $\mathrm{M} \mathrm{NaCl}$ reference electrode). Cyclic voltammograms of $\mathrm{fac}$ - $\left[\mathrm{ReCl}(\mathrm{CO})_{3}(\right.$ bipy $\left.)\right], \mathbf{1}, \mathbf{3 a - d}$, and $4 a-d$. CPEs of $\mathrm{CO}_{2}$ saturated solutions of complexes 3a (at $-2.45 \mathrm{~V}$ vs $\mathrm{Fc}^{+/ 0}, 1 \mathrm{mM}$ ), and 4a $\left(-2.62 \mathrm{~V}\right.$ vs $\left.\mathrm{Fc}^{+/ 0}, 1 \mathrm{mM}\right)$ in $0.1 \mathrm{M} \mathrm{TBAPF}_{6} / \mathrm{MeCN}$ electrolyte. Calculated energies of the Re-pzH bond for cationic complexes and for their one-reduced-electron species. (PDF)

\section{Accession Codes}

CCDC 1971286-1971288 contain the supplementary crystallographic data for this paper. These data can be obtained free of charge via www.ccdc.cam.ac.uk/data_request/cif, or by emailingdata_request@ccdc.cam.ac.uk, or by contacting The Cambridge Crystallographic Data Centre, 12 Union Road, Cambridge CB2 1EZ, UK; fax: +44 1223336033.

\section{AUTHOR INFORMATION}

\section{Corresponding Author}

Fernando Villafañe - GIR MIOMeT-IU Cinquima-Química Inorgánica, Facultad de Ciencias, Campus Miguel Delibes, Universidad de Valladolid, 47011 Valladolid, Spain; ๑ orcid.org/0000-0002-3230-3802;

Email: fernando.villafane@uva.es

\section{Authors}

Beatriz Merillas - GIR MIOMeT-IU Cinquima-Quimica Inorgánica, Facultad de Ciencias, Campus Miguel Delibes, Universidad de Valladolid, 47011 Valladolid, Spain

Elena Cuéllar - GIR MIOMeT-IU Cinquima-Quimica Inorgánica, Facultad de Ciencias, Campus Miguel Delibes, Universidad de Valladolid, 47011 Valladolid, Spain

Alberto Diez-Varga - Departamento de Quimica, Facultad de Ciencias, Universidad de Burgos, 09001 Burgos, Spain

Tomás Torroba - Departamento de Quimica, Facultad de Ciencias, Universidad de Burgos, 09001 Burgos, Spain; ○ orcid.org/0000-0002-5018-4173

Gabriel García-Herbosa - Departamento de Quimica, Facultad de Ciencias, Universidad de Burgos, 09001 Burgos, Spain; (1) orcid.org/0000-0002-2863-1272

Sergio Fernández - Institute of Chemical Research of Catalonia (ICIQ), The Barcelona Institute of Science and Technology, 43007 Tarragona, Spain; 이이이.org/0000-0002-1620-8514

Julio Lloret-Fillol - Institute of Chemical Research of Catalonia (ICIQ), The Barcelona Institute of Science and Technology, 43007 Tarragona, Spain; Catalan Institution for Research and Advanced Studies (ICREA), 08010 Barcelona, Spain;

(1) orcid.org/0000-0002-4240-9512
Jose M. Martín-Alvarez - GIR MIOMeT-IU CinquimaQuimica Inorgánica, Facultad de Ciencias, Campus Miguel Delibes, Universidad de Valladolid, 47011 Valladolid, Spain; - orcid.org/0000-0002-6969-0703

Daniel Miguel - GIR MIOMeT-IU Cinquima-Quimica Inorgánica, Facultad de Ciencias, Campus Miguel Delibes, Universidad de Valladolid, 47011 Valladolid, Spain; (- orcid.org/0000-0003-0650-3058

Complete contact information is available at: https://pubs.acs.org/10.1021/acs.inorgchem.0c01654

\section{Author Contributions}

The manuscript was written through contributions of all authors. All authors have given approval to the final version of the manuscript.

\section{Notes}

The authors declare no competing financial interest.

\section{ACKNOWLEDGMENTS}

The authors in Valladolid gratefully acknowledge financial support from the Spanish MINECO, Spain (PGC2018099470-B-I00) and Junta de Castilla y León (VA130618), and the authors in Burgos gratefully acknowledge financial support from the Junta de Castilla y León, Consejeria de Educación y Cultura y Fondo Social Europeo (Project BU263P18). E.C. thanks the UVa for her grant. We also thank the ICIQ Foundation, AGAUR 2017-SGR-1647 (J.L.-F.) and the Spanish MINECO (CTQ2016-80038-R; J.L-F.), and the Spanish Ministry of Science is acknowledged for a FPU fellowship to S.F.

\section{REFERENCES}

(1) (a) Wrighton, M.; Morse, D. L. The nature of the lowest excited state in tricarbonylchloro-1,10-phenanthrolinerhenium(I) and related complexes. J. Am. Chem. Soc. 1974, 96, 998-1003. (b) Giordano, P.; Fredericks, S.; Wrighton, M. S.; Morse, D. Simultaneous multiple emissions from fac-XRe $(\mathrm{CO})_{3}$ (3-benzoylpyridine $)_{2}: \mathrm{n}-\pi^{*}$ intraligand and charge-transfer emission at low temperature. J. Am. Chem. Soc. 1978, 100, 2257-2259. (c) Luong, J. C.; Nadjo, L.; Wrighton, M. S. Ground and excited state electron transfer processes involving factricarbonylchloro(1,10-phenanthroline)rhenium(I). Electrogenerated chemiluminescence and electron transfer quenching of the lowest excited state. J. Am. Chem. Soc. 1978, 100, 5790-5795.

(2) Some reference reviews: (a) Lees, A. J. Luminescence properties of organometallic complexes. Chem. Rev. 1987, 87, 711-743. (b) Stufkens, D. J. The remarkable properties of $\alpha$-diimine rhenium tricarbonyl complexes in their metal-to-ligand chargetransfer (MLCT) excited states. Comments Inorg. Chem. 1992, 13, 359-385. (c) Schanze, K. S.; MacQueen, D. B.; Perkins, T. A.; Cabana, L. A. Studies of intramolecular electron and energy transfer using the fac(diimine) $\operatorname{Re}^{\mathrm{I}}(\mathrm{CO})_{3}$ chromophore. Coord. Chem. Rev. 1993, 122, 6389. (d) Chen, P.; Meyer, T. J. Medium effects on charge transfer in metal complexes. Chem. Rev. 1998, 98, 1439-1477. (e) Baba, A. I.; Shaw, J. R.; Simon, J. A.; Thummel, R. P.; Schmehl, R. H. The photophysical behavior of $\mathrm{d}^{6}$ complexes having nearly isoenergetic MLCT and ligand localized excited states. Coord. Chem. Rev. 1998, 171, 43-59. (f) Stufkens, D. J.; Vlček, A., Jr. Ligand-dependent excited state behaviour of $\operatorname{Re}(\mathrm{I})$ and $\mathrm{Ru}(\mathrm{II})$ carbonyl-diimine complexes. Coord. Chem. Rev. 1998, 177, 127-179. (g) Vogler, A.; Kunkely, H. Excited state properties of organometallic compounds of rhenium in high and low oxidation states. Coord. Chem. Rev. 2000, 200-202, 991-1008. (h) Yam, V. W.-W. Luminescent carbon-rich rhenium(I) complexes. Chem. Commun. 2001, 789-796. (i) Striplin, D. R.; Crosby, G. A. Photophysical investigations of rhenium(I)Cl(CO)3(phenanthroline) complexes. Coord. Chem. Rev. 2001, 211, 
163-175. (j) Kirgan, R. A.; Sullivan, B. P.; Rillema, D. P. Photochemistry and photophysics of coordination compounds: rhenium. Top. Curr. Chem. 2007, 281, 45-100. (k) Coleman, A.; Brennan, C.; Vos, J. G.; Pryce, M. T. Photophysical properties and applications of $\operatorname{Re}(\mathrm{I})$ and $\operatorname{Re}(\mathrm{I})-\mathrm{Ru}(\mathrm{II})$ carbonyl polypyridyl complexes. Coord. Chem. Rev. 2008, 252, 2585-2595. (1) Kumar, A.; Sun, S.-S.; Lees, A. J. Photophysics and photochemistry of organometallic rhenium diimine complexes. Top. Organomet. Chem. 2009, 29, 37-71. (m) Vlček, A., Jr. Ultrafast excited-state processes in $\operatorname{Re}(\mathrm{I})$ carbonyl-diimine complexes: from excitation to photochemistry. Top. Organomet. Chem. 2009, 29, 115-158. (n) Villafañe, F. $\operatorname{Re}^{\mathrm{I}}(\mathrm{CO})_{3}$ complexes with diimine ligands synthesized in situ. Coord. Chem. Rev. 2017, 339, 128-137.

(3) Some reference reviews: (a) Lo, K. K.-W.; Hui, W.-K.; Chung, C.-K.; Tsang, K. H.-K.; Lee, T. K.-M.; Li, C.-K.; Lau, J. S.-Y.; Ng, D. C.-M. Luminescent transition metal complex biotin conjugates. Coord. Chem. Rev. 2006, 250, 1724-1736. (b) Beck, C.; Brewer, J.; Lee, J.; McGraw, D.; DeGraff, B. A.; Demas, J. N. Localizing molecular probes: inclusion of $\operatorname{Re}(\mathrm{I})$ complexes in $\beta$-cyclodextrin. Coord. Chem. Rev. 2007, 251, 546-553. (c) Fernández-Moreira, V.; ThorpGreenwood, F. L.; Coogan, M. P. Application of $\mathrm{d}^{6}$ transition metal complexes in fluorescence cell imaging. Chem. Commun. 2010, 46, 186-202. (d) Lo, K. K.-W.; Louie, M.-W.; Zhang, K. Y. Design of luminescent iridium(III) and rhenium(I) polypyridine complexes as in vitro and in vivo ion, molecular and biological probes. Coord. Chem. Rev. 2010, 254, 2603-2622. (f) Balasingham, R; Coogan, M. P.; Thorp-Greenwood, F. L. Complexes in context: attempting to control the cellular uptake and localisation of rhenium fac-tricarbonyl polypyridyl complexes. Dalton Trans. 2011, 40, 11663-11674. (g) Lo, K.-W.; Zhang, K. Y.; Li, S. P.-Y. Recent exploitation of luminescent rhenium(I) tricarbonyl polypyridine complexes as biomolecular and cellular probes. Eur. J. Inorg. Chem. 2011, 2011, 3551-3568. (h) Lo, K. K.-W.; Choi, A. W.-T.; Law, W. H.-T. Applications of luminescent inorganic and organometallic transition metal complexes as biomolecular and cellular probes. Dalton Trans. 2012, 41, 6021-6047. (i) Hostachy, S.; Policar, C.; Delsuc, N. Re(I) carbonyl complexes: multimodal platforms for inorganic chemical biology Coord. Coord. Chem. Rev. 2017, 351, 172-188. (j) Lee, L. C.C.; Leung, K.-K.; Lo, K. K.-W. Recent development of luminescent rhenium(I) tricarbonyl polypyridine complexes as cellular imaging reagents, anticancer drugs, and antibacterial agents. Dalton Trans. 2017, 46, 16357-16380. (k) Konkankit, C. C.; Marker, S. C.; Knopf, K. M.; Wilson, J. J. Anticancer activity of complexes of the third row transition metals, rhenium, osmium, and iridium. Dalton Trans. 2018, 47, 9934-9974. (e) Lo, K. K.-W. Exploitation of luminescent organometallic rhenium(I) and iridium(III) complexes in biological studies. Top. Organomet. Chem. 2010, 29, 73-114.

(4) Some reference reviews: (a) Schanze, K. S.; MacQueen, D. B.; Perkins, T. A.; Cabana, L. A. Studies of intramolecular electron and energy transfer using the fac-(diimine) $\operatorname{Re}^{\mathrm{I}}(\mathrm{CO})_{3}$ chromophore. Coord. Chem. Rev. 1993, 122, 63-89. (b) Polo, A. S.; Itokazu, M. K.; Frin, K. M.; de Toledo Patrocínio, A. O.; Murakami Iha, N. Y. M. Light driven trans-to-cis isomerization of stilbene-like ligands in fac$\left[\operatorname{Re}(\mathrm{CO})_{3}(\mathrm{NN})(\text { trans-L) }]^{+}\right.$and luminescence of their photoproducts. Coord. Chem. Rev. 2006, 250, 1669-1680.

(5) Yersin, H.; Rausch, A. F.; Czerwieniec, R.; Hofbeck, T.; Fischer, $\mathrm{T}$. The triplet state of organo-transition metal compounds. Triplet harvesting and singlet harvesting for efficient OLEDs. Coord. Chem. Rev. 2011, 255, 2622-2652.

(6) Some reference reviews: (a) Takeda, H.; Ishitani, O. Development of efficient photocatalytic systems for $\mathrm{CO}_{2}$ reduction using mononuclear and multinuclear metal complexes based on mechanistic studies. Coord. Chem. Rev. 2010, 254, 346-354. (b) Qiao, J.; Liu, Y.; Hong, F.; Zhang, J. A review of catalysts for the electroreduction of carbon dioxide to produce low-carbon fuels. Chem. Soc. Rev. 2014, 43, 631-675. (c) Francke, R.; Schille, B.; Roemelt, M. Homogeneously catalyzed electroreduction of carbon dioxide-Methods, mechanisms, and catalysts. Chem. Rev. 2018, 118, 4631-4701. (d) Kuramochi, Y.; Ishitani, O.; Ishida, H. Reaction mechanisms of catalytic photo- chemical $\mathrm{CO}_{2}$ reduction using $\mathrm{Re}(\mathrm{I})$ and $\mathrm{Ru}(\mathrm{II})$ complexes. Coord. Chem. Rev. 2018, 373, 333-356. (e) Jiang, C.; Nichols, A. W.; Machan, C. W. A look at periodic trends in d-block molecular electrocatalysts for $\mathrm{CO}_{2}$ reduction. Dalton Trans. 2019, 48, 94549468.

(7) Zarkadoulas, A.; Koutsouri, E.; Kefalidi, C.; Mitsopoulou, C. A. Rhenium complexes in homogeneous hydrogen evolution. Coord. Chem. Rev. 2015, 304-305, 55-72.

(8) Vos, J. G. Excited-state acid-base properties of inorganic compounds. Polyhedron 1992, 11, 2285-2299.

(9) Costa, I.; Montalti, M.; Pallavicini, P.; Perotti, A.; Prodi, L.; Zaccheroni, N. Absorption and luminescence as a function of $\mathrm{pH}$ for carboxylic acid-functionalized $\operatorname{Re}^{\mathrm{I}}$ tricarbonyls. J. Organomet. Chem. 2000, 593-594, 267-273.

(10) (a) Liu, W.; Heinze, K. Rhenium(I) and platinum(II) complexes with diimine ligands bearing acidic phenol substituents: hydrogen-bonding, acid-base chemistry and optical properties. Dalton Trans. 2010, 39, 9554-9564. (b) Chanawanno, K.; Engle, J. T.; Le, K. X.; Herrick, R. S.; Ziegler, C. J. The synthesis and pHdependent behaviour of $\operatorname{Re}(\mathrm{CO})_{3}$ conjugates with diimine phenolic ligands. Dalton Trans. 2013, 42, 13679-13684. (c) Taylor, J. O.; Neri, G.; Banerji, L.; Cowan, A. J.; Hartl, F. Strong Impact of Intramolecular Hydrogen Bonding on the Cathodic Path of $\left[\operatorname{Re}\left(3,3^{\prime}\right.\right.$-dihydroxy-2,2'-bipyridine $\left.)(\mathrm{CO})_{3} \mathrm{Cl}\right]$ and Catalytic Reduction of Carbon Dioxide. Inorg. Chem. 2020, 59, 5564-5578. (d) Talukdar, K.; Roy, S. S.; Amatya, E.; Sleeper, E. A.; Le Magueres, P.; Jurss, J. W. Enhanced Electrochemical CO2 Reduction by a Series of Molecular Rhenium Catalysts Decorated with SecondSphere Hydrogen-Bond Donors. Inorg. Chem. 2020, 59, 6087-6099.

(11) Tzeng, B.-C.; Chen, B.-S.; Chen, C.-K.; Chang, Y.-P.; Tzeng, W.-C.; Lin, T.-Y.; Lee, G.-H.; Chou, P.-T.; Fu, Y.-J.; Chang, A. H.-H. $\mathrm{pH}-\mathrm{Dependent}$ spectroscopic and luminescent properties, and metalion recognition studies of $\operatorname{Re}(\mathrm{I})$ complexes containing $2-\left(2^{\prime}\right.$ pyridyl)benzimidazole and 2-(2'-pyridyl)benzimidazolate. Inorg. Chem. 2011, 50, 5379-5388.

(12) (a) Ko, C.-C.; Ng, C.-O.; Yiu, S.-M. Luminescent rhenium(I) phenanthroline complexes with a benzoxazol-2-ylidene ligand: synthesis, characterization, and photophysical study. Organometallics 2012, 31, 7074-7084. (b) Werrett, M. V.; Muzzioli, S.; Wright, P. J.; Palazzi, A.; Raiteri, P.; Zacchini, S.; Massi, M.; Stagni, S. Protoninduced reversible modulation of the luminescent output of rhenium(I), iridium(III), and ruthenium(II) tetrazolate complexes. Inorg. Chem. 2014, 53, 229-243.

(13) (a) Bronner, C.; Wenger, O. S. Proton-coupled electron transfer between 4-cyanophenol and photoexcited rhenium(I) complexes with different protonatable sites. Inorg. Chem. 2012, 51, 8275-8283. (b) Kuss-Petermann, M.; Wolf, H.; Stalke, D.; Wenger, O. S. Influence of donor-acceptor distance variation on photoinduced electron and proton transfer in rhenium(I)-phenol dyads. J. Am. Chem. Soc. 2012, 134, 12844-12854. (c) Bonn, A. G.; Neuburger, M.; Wenger, O. S. Photoinduced electron transfer in rhenium(I)-oligotriarylamine molecules. Inorg. Chem. 2014, 53, 11075-11085.

(14) Gómez-Iglesias, P.; Guyon, F.; Khatyr, A.; Ulrich, G.; Knorr, M.; Martín-Alvarez, J. M.; Miguel, D.; Villafañe, F. Luminescent rhenium(I) tricarbonyl complexes with pyrazolylamidino ligands: photophysical, electrochemical, and computational studies. Dalton Trans. 2015, 44, 17516-17528.

(15) Merillas, B.; Cuéllar, E.; Diez-Varga, A.; Asensio-Bartolomé, M.; García-Herbosa, G.; Torroba, T.; Martín-Alvarez, J. M.; Miguel, D.; Villafañe, F. Whole microwave syntheses of pyridylpyrazole and of Re and $\mathrm{Ru}$ luminescent pyridylpyrazole complexes. Inorg. Chim. Acta 2019, 484, 1-7.

(16) Ranjan, S.; Lin, S.-Y.; Hwang, K.-C.; Chi, Y.; Ching, W.-L.; Liu, C.-S.; Tao, Y.-T.; Chien, C.-H.; Peng, S.-M.; Lee, G.-H. Realizing green phosphorescent light-emitting materials from rhenium(I) pyrazolato diimine complexes. Inorg. Chem. 2003, 42, 1248-1255. 
(17) Costentin, C.; Drouet, S.; Robert, M.; Saveant, J. M. A local proton source enhances $\mathrm{CO}_{2}$ electroreduction to $\mathrm{CO}$ by a molecular Fe catalyst. Science 2012, 338, 90-94.

(18) (a) Manbeck, G. F.; Muckerman, J. T.; Szalda, D. J.; Himeda, Y.; Fujita, E. Push or pull? Proton responsive ligand effects in rhenium tricarbonyl $\mathrm{CO}_{2}$ reduction catalysts. J. Phys. Chem. B 2015, 119, 7457-7466. (b) Machan, C. W.; Yin, J.; Chabolla, S. A.; Gilson, M. K.; Kubiak, C. P. Improving the efficiency and activity of electrocatalysts for the reduction of $\mathrm{CO}_{2}$ through supramolecular assembly with amino acid-modified ligands. J. Am. Chem. Soc. 2016, 138, 8184-8193. (c) Wilting, A.; Stolper, T.; Mata, R. A.; Siewert, I. Dinuclear rhenium complex with a proton responsive ligand as a redox catalyst for the electrochemical $\mathrm{CO}_{2}$ reduction. Inorg. Chem. 2017, 56, 4176-4185. (d) Sinha, S.; Berdichevsky, E. K.; Warren, J. J. Electrocatalytic $\mathrm{CO}_{2}$ reduction using rhenium(I) complexes with modified 2-(2'-pyridyl)imidazole ligands. Inorg. Chim. Acta 2017, 460, 63-68. (e) Sung, S.; Kumar, D.; Gil-Sepulcre, M.; Nippe, M. Electrocatalytic $\mathrm{CO}_{2}$ reduction by imidazolium-functionalized molecular catalysts. J. Am. Chem. Soc. 2017, 139, 13993-13996. (f) Rotundo, L.; Garino, C.; Priola, E.; Sassone, D.; Rao, H.; Ma, B.; Robert, M.; Fiedler, J.; Gobetto, R.; Nervi, C. Electrochemical and photochemical reduction of $\mathrm{CO}_{2}$ catalyzed by $\operatorname{Re}(\mathrm{I})$ complexes carrying local proton sources. Organometallics 2019, 38, 1351-1360. (g) Das, T.; Rajak, K. K. Experimental and theoretical investigation of a metalloreceptor bearing a $\left[\operatorname{Re}(\mathrm{CO})_{3}\right]^{+}$core incorporating a multifunctional ligand: selective reactivity towards $\mathrm{Zn}^{2+}$ and $\mathrm{CN}^{-}$ ions. Dalton Trans. 2019, 48, 6879-6891.

(19) Arroyo, M.; Gómez-Iglesias, P.; Antón, N.; García-Rodríguez, R.; Alegria, E. C. B. A.; Pombeiro, A. J. L.; Miguel, D.; Villafañe, F. Homo- and heteropolymetallic 3-(2-pyridyl)pyrazolate manganese and rhenium complexes. Dalton Trans. 2014, 43, 4009-4020.

(20) See for example: (a) Lytwak, L. A.; Stanley, J. M.; Mejía, M. L.; Holliday, B. J. Synthesis, characterization, and photophysical properties of a thiophene-functionalized bis(pyrazolyl) pyridine (BPP) tricarbonyl rhenium(I) complex. Dalton Trans. 2010, 39, 7692-7699. (b) Wei, Q.-H.; Xiao, F.-N.; Han, L.-J.; Zeng, S.-L.; Duan, Y.-N.; Chen, G.-N. Synthesis, structure, photophysical and electrochemiluminescence properties of $\operatorname{Re}(\mathrm{I})$ tricarbonyl complexes incorporating pyrazolyl-pyridyl-based ligands. Dalton Trans. 2011, 40, 5078-5085. (c) Sangilipandi, S.; Nagarajaprakash, R.; Sutradhar, D.; Kaminsky, W.; Chandra, A. K.; Mohan Rao, K. Synthesis, molecular structural studies and DFT calculations of tricarbonylrhenium(I) metal complexes containing nitrogen based $\mathrm{N} \cap \mathrm{N}$ donor polypyridyl ligands. Inorg. Chim. Acta 2015, 437, 177-187. (d) Saad, S. T.; Metherell, A. J.; Baggaley, E.; Ward, M. D. Synthesis and photophysical properties of $\operatorname{Ir}(\mathrm{III}) / \operatorname{Re}(\mathrm{I})$ dyads: control of $\mathrm{Ir} \rightarrow \operatorname{Re}$ photoinduced energy transfer. Dalton Trans. 2016, 45, 11568-11579. (e) Sangilipandi, S.; Sutradhar, D.; Bhattacharjee, K.; Kaminsky, W.; Joshi, S.R.; Chandra, A. K.; Mohan Rao, K. Synthesis, structure, antibacterial studies and DFT calculations of arene ruthenium, $\mathrm{CpRh}, \mathrm{CpIr}$ and tricarbonylrhenium metal complexes containing 2-chloro-3-(3-(2-pyridyl)pyrazolyl)quinoxaline ligand. Inorg. Chim. Acta 2016, 441, 95-108.

(21) (a) Jeffrey, G. A. An Introduction to Hydrogen Bonding; Oxford University Press, New York, 1997; Ch. 2. (b) Steiner, T. The Hydrogen Bond in the Solid State. Angew. Chem., Int. Ed. 2002, 41, $48-76$.

(22) (a) Catalan, J.; Claramunt, R. M.; Elguero, J.; Laynez, J.; Menendez, M.; Anvia, F.; Quian, J. H.; Taagepera, M.; Taft, R. W. Basicity and Acidity of Azoles: The annelation effect in azoles. J. Am. Chem. Soc. 1988, 110, 4105-4111. (b) Elguero, J.; Yranzo, G. I.; Laynez, J.; Jimenez, P.; Menendez, M.; Catalan, J.; De Paz, J. L. G.; Anvia, F.; Taft, R. W. Effect of the replacement of a methyl by a trifluoromethyl group on the acid-base properties of pyrazoles. J. Org. Chem. 1991, 56, 3942-3947.

(23) Wright, P. J.; Affleck, M. G.; Muzzioli, S.; Skelton, B. W.; Raiteri, P.; Silvester, D. S.; Stagni, S.; Massi, M. Ligand-induced structural, photophysical, and electrochemical variations in tricarbonyl rhenium(I) tetrazolato complexes. Organometallics 2013, 32, 37283737.
(24) Werrett, M. V.; Chartrand, D.; Gale, J. D.; Hanan, G. S.; MacLellan, J. G.; Massi, M.; Muzzioli, S.; Raiteri, P.; Skelton, B. W.; Silberstein, M.; Stagni, S. Synthesis, structural, and photophysical investigation of diimine triscarbonyl $\operatorname{Re}(\mathrm{I})$ tetrazolato complexes. Inorg. Chem. 2011, 50, 1229-1241.

(25) (a) Shavaleev, N. M.; Bell, Z. R.; Easun, T. L.; Rutkaite, R.; Swanson, L.; Ward, M. D. Complexes of substituted derivatives of 2(2-pyridyl)benzimidazole with $\operatorname{Re}(\mathrm{I}), \mathrm{Ru}(\mathrm{II})$ and $\mathrm{Pt}(\mathrm{II})$ : structures, redox and luminescence properties. Dalton Trans. 2004, 3678-3688. (b) Obata, M.; Kitamura, A.; Mori, A.; Kameyama, C.; Czaplewska, J. A.; Tanaka, R.; Kinoshita, I.; Kusumoto, T.; Hashimoto, H.; Harada, M.; Mikata, Y.; Funabiki, T.; Yano, S. Syntheses, structural characterization and photophysical properties of 4-(2-pyridyl)-1,2,3triazole rhenium(I) complexes. Dalton Trans. 2008, 3292-3300. (c) Wolff, M.; Munoz, L.; François, A.; Carrayon, C.; Seridi, A.; Saffon, N.; Picard, C.; Machura, B.; Benoist, E. Tricarbonylrhenium complexes from 2-pyridyl-1,2,3-triazole ligands bearing a 4-substituted phenyl arm: a combined experimental and theoretical study. Dalton Trans. 2013, 42, 7019-7031. (d) Klemens, T.; Czerwińska, K.; Szlapa-Kula, A.; Kula, S.; Switlicka, A.; Kotowicz, S.; Siwy, M.; Bednarczyk, K.; Krompiec, S.; Smolarek, K.; Maćkowski, S.; Danikiewicz, W.; Schab-Balcerzak, E.; Machura, B. Synthesis, spectroscopic, electrochemical and computational studies of rhenium(I) tricarbonyl complexes based on bidentate-coordinated 2,6di(thiazol-2-yl)pyridine derivatives. Dalton Trans. 2017, 46, 96059620.

(26) Cattaneo, M.; Fagalde, F.; Katz, N. E. Proton-induced luminescence of mono- and dinuclear rhenium(I) tricarbonyl complexes containing 4-pyridinealdazine. Inorg. Chem. 2006, 45, 6884-6891.

(27) Gritzner, G.; Kuta, J. Recommendations on reporting electrode potentials in nonaqueous solvents. Pure Appl. Chem. 1984, 56, 461466.

(28) Hawecker, J.; Lehn, J.-M.; Ziessel, R. Electrocatalytic reduction of carbon dioxide mediated by $\operatorname{Re}($ bipy $)(\mathrm{CO})_{3} \mathrm{Cl}$ (bipy $=2,2^{\prime}$ bipyridine). J. Chem. Soc., Chem. Commun. 1984, 328-330.

(29) Bullock, J. P.; Carter, E.; Johnson, R.; Kennedy, A. T.; Key, S. E.; Kraft, B. J.; Saxon, D.; Underwood, P. Reactivity of electrochemically generated rhenium (II) tricarbonyl $\alpha$-diimine complexes: a reinvestigation of the oxidation of luminescent $\operatorname{Re}(\mathrm{CO})_{3}(\alpha$-diimine $)$ $\mathrm{Cl}$ and related compounds. Inorg. Chem. 2008, 47, 7880-7887.

(30) Klein, A.; Vogler, C.; Kaim, W. The $\delta$ in $18+\delta$ electron complexes: importance of the metal/ligand interface for the substitutional reactivity of " $\operatorname{Re}(0)$ " complexes $\left(\delta\right.$-diimine $\left.{ }^{-}\right)$$\operatorname{Re}^{\mathrm{I}}(\mathrm{CO})_{3}(\mathrm{X})$. Organometallics 1996, 15, 236-244.

(31) Anderson, C. B.; Elliott, A. B. S.; McAdam, C. J.; Gordon, K. C.; Crowley, J. D. fac- $\mathrm{Re}(\mathrm{CO})_{3} \mathrm{Cl}$ complexes of [2-(4-R-1H-1,2,3Triazol-1-yl)methyl]pyridine inverse "click" ligands: a systematic synthetic, spectroscopic, and computational study. Organometallics 2013, 32, 788-797.

(32) (a) Zeng, Q.; Messaoudani, M.; Vlček, A.; Hartl, F. Electrochemical reductive deprotonation of an imidazole ligand in a bipyridine tricarbonyl rhenium(I) complex. Eur. J. Inorg. Chem. 2012, 2012, 471-474. (b) Zeng, Q.; Messaoudani, M.; Vlček, A.; Hartl, F. Temperature-dependent reduction pathways of complexes fac-[Re$(\mathrm{CO})_{3}(\mathrm{~N}-\mathrm{R}$-imidazole $)(1,10$-phenanthroline $\left.)\right]^{+}\left(\mathrm{R}=\mathrm{H}, \mathrm{CH}_{3}\right)$. Electrochim. Acta 2013, 110, 702-708.

(33) Perrin, D. D.; Armarego, W. L. F. Purification of Laboratory Chemicals, 3rd ed.; Pergamon Press: Oxford, 1988.

(34) ${ }^{1} \mathrm{H}$ NMR $\left(\mathrm{CD}_{3} \mathrm{NO}_{2}\right): \delta: 7.13\left(\mathrm{~d}, J=2.8 \mathrm{~Hz}, H^{4}, 1 \mathrm{H}\right), 7.54(\mathrm{dd}$, $J=4.8$ y $\left.2.8 \mathrm{~Hz}, H^{5 \prime}, 1 \mathrm{H}\right), 7.96\left(\mathrm{~d}, J=2.8 \mathrm{~Hz}, H^{5}, 1 \mathrm{H}\right), 8.13\left(\mathrm{~m}, H^{4 \prime}\right.$ and $\left.H^{3 \prime}, 2 \mathrm{H}\right), 9.0\left(\mathrm{~d}, J=5.2 \mathrm{~Hz}, H^{6 \prime}, 1 \mathrm{H}\right), 12.90$ (br s, NH, $\left.1 \mathrm{H}\right)$. In other solvents, the ${ }^{1} \mathrm{H}$ NMR spectra display a mixture of compounds as a result of the substitution of the triflate ligand by residual THF and/or the deuterated solvent. IR (THF, $\mathrm{cm}^{-1}$ ): $2035 \mathrm{~s}, 1933 \mathrm{~s}, 1910$ s, assigned to $f a c-\left[\operatorname{Re}(\mathrm{CO})_{3}(\right.$ pypzH $)($ thf $\left.)\right]$ OTf.

(35) (a) Fujita, E.; Creutz, C.; Sutin, N.; Szalda, D. J. Carbon dioxide activation by cobalt(I) macrocycles: factors affecting carbon dioxide and carbon monoxide binding. J. Am. Chem. Soc. 1991, 113, 
343-353. (b) Gennaro, A.; Isse, A. A.; Vianello, E. Solubility and electrochemical determination of carbon dioxide in some dipolar aprotic solvents. J. Electroanal. Chem. Interfacial Electrochem. 1990, 289, 203-215.

(36) Frisch, M. J.; Trucks, G. W.; Schlegel, H. B.; Scuseria, G. E.; Robb, M. A.; Cheeseman, J. R.; Scalmani, G.; Barone, V.; Petersson, G. A.; Nakatsuji, H.; Li, X.; Caricato, M.; Marenich, A. V.; Bloino, J.; Janesko, B. G.; Gomperts, R.; Mennucci, B.; Hratchian, H. P.; Ortiz, J. V.; Izmaylov, A. F.; Sonnenberg, J. L.; Williams-Young, D.; Ding, F.; Lipparini, F.; Egidi, F.; Goings, J.; Peng, B.; Petrone, A.; Henderson, T.; Ranasinghe, D.; Zakrzewski, V. G.; Gao, J.; Rega, N.; Zheng, G.; Liang, W.; Hada, M.; Ehara, M.; Toyota, K.; Fukuda, R.; Hasegawa, J.; Ishida, M.; Nakajima, T.; Honda, Y.; Kitao, O.; Nakai, H.; Vreven, T.; Throssell, K.; Montgomery, J. A., Jr.; Peralta, J. E.; Ogliaro, F.; Bearpark, M.; Heyd, J. J.; Brothers, E. N.; Kudin, K. N.; Staroverov, V. N.; Kobayashi, R.; Normand, J.; Raghavachari, K.; Rendell, A.; Burant, J. C.; Iyengar, S. S.; Tomasi, J.; Cossi, M.; Millam, J. M.; Klene, M.; Adamo, C.; Cammi, R.; Ochterski, J. W.; Martin, R. L.; Morokuma, K.; Farkas, O.; Foresman, J. B.; Fox, D. J. Gaussian 16, revision A.03; Gaussian, Inc.: Wallingford CT, 2016.

(37) (a) Becke, A. D. Density-functional thermochemistry. III. The role of exact exchange. J. Chem. Phys. 1993, 98, 5648-5652. (b) Lee, C.; Yang, W.; Parr, R. G. Development of the Colle-Salvetti correlation-energy formula into a functional of the electron density. Phys. Rev. B: Condens. Matter Mater. Phys. 1988, 37, 785. (c) Hay, P. J.; Wadt, W. R. Ab initio effective core potentials formolecular calculations. Potentials for $\mathrm{K}$ toAu including the outermost core orbitals. J. Chem. Phys. 1985, 82, 299-310.

(38) (a) Helgaker, T.; Jo/rgensen, P. An electronic Hamiltonian for originindependent calculations of magneticproperties. J. Chem. Phys. 1991, 95, 2595-2601. (b) Bak, K. L.; Jo/rgensen, P.; Helgaker, T.; Ruud, K.; Jensen, H. J. A. Gauge-origin independentmulticonfigurational self-consistent-fieldtheory for vibrational circular dichroism. J. Chem. Phys. 1993, 98, 8873-8887. (c) Autschbach, J.; Ziegler, T.; van Gisbergen, S. J. A.; Baerends, E. J. Chiroptical properties from timedependent density functional theory. I. Circular dichroism spectra of organic molecules. J. Chem. Phys. 2002, 116, 6930-6940.

(39) (a) Hay, P. J.; Wadt, W. R. Ab initio effective core potentials for molecular calculations. Potentials for the transition metal atoms $\mathrm{Sc}$ to Hg. J. Chem. Phys. 1985, 82, 270-283. (b) Hay, P. J.; Wadt, W. R. Ab initio effective core potentials for molecular calculations. Potentials for $\mathrm{K}$ to Au including the outermost core orbitals. J. Chem. Phys. 1985, 82, 299-310.

(40) (a) Gabrielsson, A.; Matousek, P.; Towrie, M.; Hartl, F.; Zalis, S.; Vlček, A., Jr. Excited states of nitro-polypyridine metal complexes and their ultrafast decay. Time-resolved IR absorption, spectroelectrochemistry, and TD-DFT calculations of fac- $\left[\mathrm{Re}(\mathrm{Cl})(\mathrm{CO})_{3}(5-\right.$ Nitro-1,10-phenanthroline)]. J. Phys. Chem. A 2005, 109, 6147-6153. (b) Dattelbaum, D. M.; Omberg, K. M.; Hay, P. J.; Gebhart, N. L.; Martin, R. L.; Schoonover, J. R.; Meyer, T. J. Defining electronic excited states using time-resolved infrared spectroscopy and density functional theory calculations. J. Phys. Chem. A 2004, 108, 35273536. (c) Dattelbaum, D. M.; Martin, R. L.; Schoonover, J. R.; Meyer, T. J. Molecular and electronic structure in the metal-to-ligand charge transfer excited states of fac- $\left[\operatorname{Re}\left(4,4^{\prime}-\mathrm{X}_{2} \text { bpy }\right)(\mathrm{CO})_{3}(4-\text {-Etpy })\right]^{+*}(\mathrm{X}=$ $\left.\mathrm{CH}_{3}, \mathrm{H}, \mathrm{CO}_{2} \mathrm{Et}\right)$. Application of density functional theory and timeresolved infrared spectroscopy. J. Phys. Chem. A 2004, 108, 35183526. (d) Lundin, N. J.; Walsh, P. J.; Howell, S. L.; McGarvey, J. J.; Blackman, A. G.; Gordon, K. C. Complexes of functionalized dipyrido[3,2-a:2',3'-c]-phenazine: a synthetic, spectroscopic, structural, and density functional theory study. Inorg. Chem. 2005, 44, $3551-3560$.

(41) (a) Gorelsky, S. I. AOMix: Program for Molecular Orbital Analysis, version 6.5; University of Ottawa, 2011. http://www.sgchem.net/ (b) Gorelsky, S. I.; Lever, A. B. P. Electronic structure and spectra of ruthenium diimine complexes by density functional theory and INDO/S. Comparison of the two methods. J. Organomet. Chem. 2001, 635, 187-196.
(42) Dennington, R.; Keith, T.; Millam, J. GaussView, version 5; Semichem Inc.: Shawnee Mission, KS, 2009. 